\title{
Design and control of different pressure thermally coupled reactive distillation for synthesis of isoamyl acetate
}

DOI:

10.1016/j.cep.2019.03.014

\section{Document Version}

Accepted author manuscript

Link to publication record in Manchester Research Explorer

\section{Citation for published version (APA):}

Li, J., Zhou, H., Sun, L., \& Zhang, N. (2019). Design and control of different pressure thermally coupled reactive distillation for synthesis of isoamyl acetate. Chemical Engineering and Processing - Process Intensification, 51-67. https://doi.org/10.1016/j.cep.2019.03.014

\section{Published in:}

Chemical Engineering and Processing - Process Intensification

\section{Citing this paper}

Please note that where the full-text provided on Manchester Research Explorer is the Author Accepted Manuscript or Proof version this may differ from the final Published version. If citing, it is advised that you check and use the publisher's definitive version.

\section{General rights}

Copyright and moral rights for the publications made accessible in the Research Explorer are retained by the authors and/or other copyright owners and it is a condition of accessing publications that users recognise and abide by the legal requirements associated with these rights.

\section{Takedown policy}

If you believe that this document breaches copyright please refer to the University of Manchester's Takedown Procedures [http://man.ac.uk/04Y6Bo] or contact uml.scholarlycommunications@manchester.ac.uk providing relevant details, so we can investigate your claim.

\section{OPEN ACCESS}




\section{Accepted Manuscript}

Title: Design and Control of Different Pressure Thermally Coupled Reactive Distillation for Synthesis of Isoamyl Acetate

Author: Jun Li Hao Zhou Lanyi Sun Nan Zhang

PII: $\quad$ S0255-2701(18)31460-0

DOI: $\quad$ https://doi.org/doi:10.1016/j.cep.2019.03.014

Reference: $\quad$ CEP 7493

To appear in: $\quad$ Chemical Engineering and Processing

Received date: $\quad 29$ November 2018

Revised date: $\quad 26$ February 2019

Accepted date: $\quad 19$ March 2019

Please cite this article as: J. Li, H. Zhou, L. Sun, N. Zhang, Design and Control of Different Pressure Thermally Coupled Reactive Distillation for Synthesis of Isoamyl Acetate, Chemical Engineering and Processing (2019), https://doi.org/10.1016/j.cep.2019.03.014

This is a PDF file of an unedited manuscript that has been accepted for publication. As a service to our customers we are providing this early version of the manuscript. The manuscript will undergo copyediting, typesetting, and review of the resulting proof before it is published in its final form. Please note that during the production process errors may be discovered which could affect the content, and all legal disclaimers that apply to the journal pertain. 


\title{
Design and Control of Different Pressure Thermally Coupled Reactive Distillation for Synthesis of Isoamyl Acetate
}

\author{
Jun $\mathrm{Li}^{1,2}$; Hao Zhou ${ }^{1}$; Lanyi Sun ${ }^{1 *}$; Nan Zhang ${ }^{2 * *}$
}

1. State Key Laboratory of Heavy Oil Processing, China University of Petroleum, Qingdao 266580, China

2. Centre for Process Integration, School of Chemical Engineering and Analytical Science, The University of Manchester, Manchester M13 9PL, United Kingdom

\section{KEYWORDS}

Esterification; Reactive Distillation; Isoamyl Acetate; Optimization; Control.

\section{HIGHLIGHTS}

- DPTCRD process for isoamyl acetate synthesis was proposed.

- Optimized process can save $39.65 \%$ on energy cost.

- TAC can be saved up to $19.05 \%$ with payback period of 10 years.

- Feed composition - feed ratio cascade structure showed best control behaviors.

\section{ABSTRACT}

In this paper, a steady state model and three control structures of different pressure thermally coupled reactive distillation process for isoamyl acetate synthesis are proposed. The process is firstly designed in Aspen Plus to 
build a steady state model, economic analysis is then adopted to optimize process parameters. The optimized process shows $39.65 \%$ saving on operating cost and 1.25-19.05\% saving on TAC with the payback period varies from 5 to 10 years. Three control structures including one basic structure (BC) and two improved structures (IC1, IC2) are proposed. IC1 uses a composition/feed ratio controller to decrease residual errors, and a feed composition ratio controller is added in IC2 to achieve better control behaviors. $\pm 10 \%$ feed flowrate/feed water composition disturbances are added to the control structures and the control behaviors are studied. The selections of control structures are based on the control behaviors. IC2 with better control behaviors under feed composition disturbance is recommend for the process.

\section{Introduction}

Distillation is one of the most widely-used unit operations to separate mixtures in chemical industry application, which also has a disadvantage of high energy consumption, thus different types of energy-saving distillation structures are proposed. Different pressure thermally coupled distillation (DPTCD) is a kind of energy-saving distillation, which has been extensively studied in recent years. DPTCD operates two or more columns at different pressures to extract heat from lower grade energy sources. For the most typical DPTCD structure with two columns, the top vapor stream of the column with higher pressure (HP) is transported into the reboiler of the column with lower pressure (LP) as energy source. Such structure is feasible because different operation pressure means the temperature difference between the columns, which the top temperature of the HP can be higher than the bottom temperature of LP in such situation, and the reduction of energy consumption and total annual cost (TAC) can be achieved [1-3]. For further research, different pressure thermally coupled reactive distillation 
(DPTCRD) is proposed to apply conventional reactive distillation (CRD) in DPTCD process via a reaction zone.

Researches on DPTCRD process are concentrated on synthesis, hydrolysis and transesterification of esters [4-7].

Isoamyl acetate( $\mathrm{i}-\mathrm{AmAc})$ is widely used in food and chemical industry as a food additive for its special banana flavor [8]. I-AmAc can be obtained from natural plant materials, while the natural source ester is too expensive for food processing, thus the industrial production process for i-AmAc synthesis is carried out $[9,10]$. Romero et al. [9] developed a reaction mechanism for i-AmAc synthesis via the acylation between isoamyl alcohol (i$\mathrm{AmOH}$ ) and acetic anhydride using the lipase Novozym 435 in n-hexane, and the rate equations for the reaction were also proposed. Lee et al. [11] focused on the reaction equilibrium of the esterification of acetic acid (HAc) with $\mathrm{i}-\mathrm{AmOH}$, and the vapor-liquid equilibrium data of the four components in the system were also investigated. Osorio-Viana et al. [12] studied the catalytic esterification of HAc with i-AmOH over Amberlite IR-120, and twelve different kinetic models were evaluated to describe the kinetic behaviors. Besides the basic reaction research, different processes were designed to synthesis i-AmAc. Saha et al. [13] provided a CRD process for the synthesis of $\mathrm{i}-\mathrm{AmAc}$ via the esterification of $\mathrm{i}-\mathrm{AmOH}$ and $\mathrm{HAc}$, and a cation exchange resin catalyst named Purolite CT-175 was used in the catalytic reactive section. Ali et al. [14] compared the CRD process with the conventional reactor-separator process on synthesis of i-AmAc, which confirmed that the CRD process showed advantages on both energy consumption and capital cost. Further research on dynamic behaviors of the i-AmAc CRD synthesis process was also provided in the paper of Ali and his coworkers [14]. However, DPTCRD process for i-AmAc synthesis has not been proposed so far. Since DPTCRD processes usually show reduction on energy consumption compared with CRD processes, the research on the DPTCRD process for i-AmAc synthesis is of great importance. 
Since DPTCRD process combines CRD process and DPTCD process in a single process, the research on the control strategies of DPTCRD process is meaningful. Basic control structure for CRD process have been provided by Luyben [15], which include a feed ratio controller on each feed stream, and a composition controller on a product stream. Li et al. [6] applied two different control structures on DPTCRD process for methyl acetate hydrolysis and proposed a temperature/pressure cascade control structure that could provide stable control behaviors.

In this paper, a DPTCRD process for i-AmAc synthesis was proposed based on the simulation results of Aspen Plus, and the parameters of the process were optimized based on the comparison of the energy cost and TAC between the DPTCRD and the CRD processes. The optimized DPTCRD process was then imported into Aspen Dynamics to develop control structures, and three control structures with different control behaviors under feed flowrate and composition disturbance were proposed.

\section{Process description}

This work considered the production of i-AmAc by the esterification over Amberlite IR-120, and the esterification reaction can be described by expression (1):

$$
\mathrm{i}-\mathrm{AmOH}+\mathrm{HAc} \square \quad \mathrm{i}-\mathrm{AmAc}+\mathrm{H}_{2} \mathrm{O}
$$

Wilmar Osorio-Viana et al. [12] provided several kinetic models for the esterification reaction of i-AmAc over

Amberlite IR-120, and a pseudo-homogeneous model could be described by expression (2) and expression (3):

$$
\begin{gathered}
r=\mathrm{k}\left(x_{\mathrm{HAc}}-x_{\mathrm{i}-\mathrm{AmOH}}-\frac{x_{\mathrm{i}-\mathrm{AmAc}} x_{\mathrm{Water}}}{\mathrm{K}_{\mathrm{eq}}}\right) \\
\ln k(T)=\ln k_{0}\left(T_{0}\right)-\frac{\mathrm{E}_{\mathrm{a}}}{\mathrm{R}}\left(\frac{1}{T}-\frac{1}{T_{0}}\right)
\end{gathered}
$$


where $r\left(\mathrm{~mol} / \mathrm{g}^{\text {cat }} \cdot \mathrm{h}\right)$ is the reaction rate, $\mathrm{k}\left(\mathrm{mol} / \mathrm{g}^{\mathrm{cat}} \cdot \mathrm{h}\right)$ is the reaction rate constant, $T_{0}(\mathrm{~K})$ is the reference temperature, $k_{0}\left(\mathrm{~mol} / \mathrm{g}^{\text {cat }} \cdot \mathrm{h}\right)$ is the reaction rate constant under $T_{0}, \mathrm{E}_{\mathrm{a}}(\mathrm{kJ} / \mathrm{mol})$ is the reaction activation energy, $\mathrm{R}$ $(=8.314 \mathrm{~kJ} /(\mathrm{kmol} \cdot \mathrm{K}))$ is the gas constant, $\mathrm{K}_{\text {eq }}$ is the equilibrium constant, $x_{\mathrm{i}}$ is the molar fraction of component $\mathrm{i}$. In this model, $T_{0}=363.15 \mathrm{~K}, \ln k_{0}\left(T_{0}\right)=-0.349 \mathrm{~mol} / \mathrm{g}^{\text {cat }} . \mathrm{h}, E_{a}=53 \mathrm{~kJ} / \mathrm{mol}, \ln \left(\mathrm{K}_{\mathrm{eq}}\right)=1.618$. Liquid holdup was calculated based on the column diameter with $10 \mathrm{~cm}$ weir height with a density of $770 \mathrm{~kg} / \mathrm{m}^{3}$ catalyst occupied half of the tray holdup volume.

NTRL model was applied in this process to predict the equilibrium performance. Osorio-Viana and his coworkers [16] proposed a set of parameters of NRTL activity model for the quaternary mixture of HAc/i-AmOH/iAmAc/water, and the parameters used in this paper are listed in Table 1.

Table 1. NTRL activity model parameters for $\mathrm{HAc} / \mathrm{i}-\mathrm{AmAc} / \mathrm{i}-\mathrm{AmOH} /$ water mixture

\begin{tabular}{lllllll}
\hline Component $\mathrm{i}$ & HAc & Water & Water & HAc & HAc & i-AmOH \\
Component $\mathrm{j}$ & water & $\mathrm{i}-\mathrm{AmOH}$ & $\mathrm{i}-\mathrm{AmAc}$ & $\mathrm{i}-\mathrm{AmOH}$ & $\mathrm{i}-\mathrm{AmAc}$ & $\mathrm{i}-\mathrm{AmAc}$ \\
\hline Source & $\mathrm{A}^{*}$ & $\mathrm{O} * *$ & $\mathrm{O}$ & $\mathrm{O}$ & $\mathrm{O}$ & $\mathrm{O}$ \\
\hline $\mathrm{A}_{\mathrm{ij}}$ & -1.9763 & 1.5598 & 0.3194 & 0.4512 & -0.6992 & 0.1291 \\
$\mathrm{~A}_{\mathrm{ji}}$ & 3.3293 & -1.0959 & -2.5596 & 1.1307 & 0.0741 & 1.5083 \\
$\mathrm{~B}_{\mathrm{ij}}$ & 609.889 & 1096.2 & 1180.36 & -335.922 & 74.071 & -229.613 \\
$\mathrm{~B}_{\mathrm{ji}}$ & -723.888 & 166.234 & 996.942 & -53.1049 & 440.982 & -311.056 \\
$\mathrm{C}_{\mathrm{ij}}$ & 0.3 & 0.2 & 0.2 & 0.3 & 0.3 & 0.3 \\
\hline
\end{tabular}

*. Values taken from Aspen Plus (A)

**. Values taken from the paper of Osorio-Viana et al. (O)

The ternary diagrams simulated by Aspen Plus for $\mathrm{HAc} / \mathrm{i}-\mathrm{AmOH} / \mathrm{i}-\mathrm{AmAc} /$ water mixture were provided in

Figure 1. A two-liquid-phase area was predicted by the simulation results, which indicated that high-purity water 
can be obtained by liquid phase separation, and a L/L splitter can be taken into consideration in subsequent distillation design.
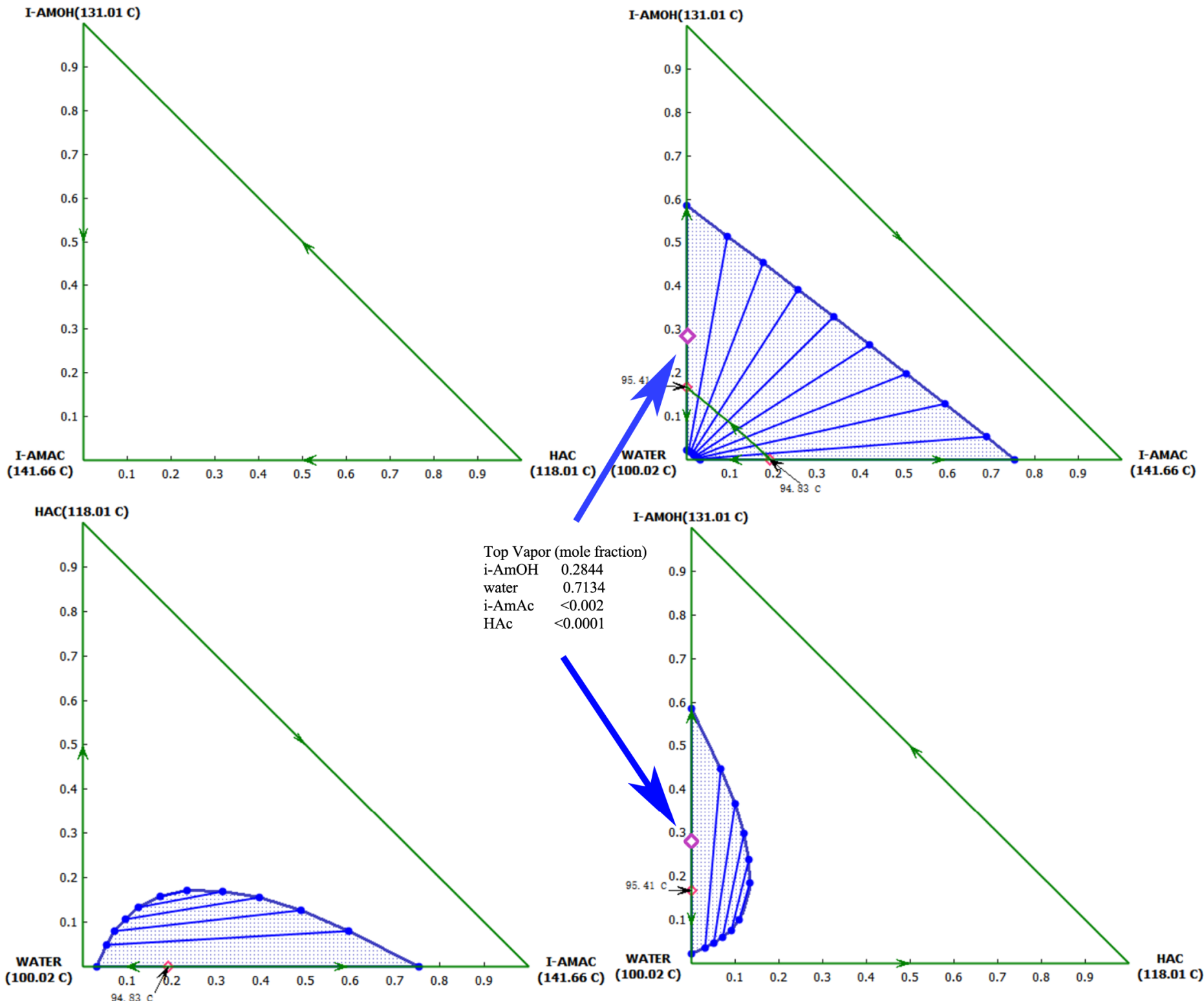

I-АМОН(131.01 C)

(mole fraction) 0.2844

$\quad 0.7134$

\begin{tabular}{lr} 
AmAc & $<0.002$ \\
\hline Ac & $<0.0001$
\end{tabular}

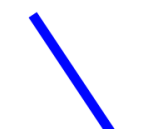

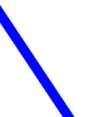
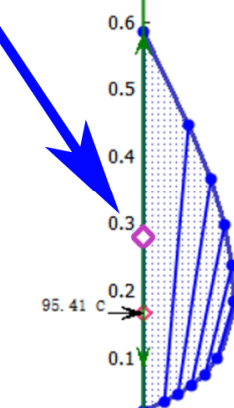

I-AMAC

(141.66 C) (100.02

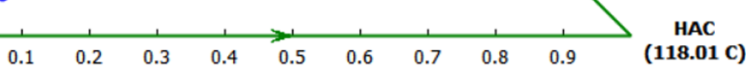

Figure 1. Ternary diagrams for $\mathrm{HAc} / \mathrm{i}-\mathrm{AmOH} / \mathrm{i}-\mathrm{AmAc} /$ water mixture system

\subsection{CRD Process}


The CRD process for synthesis of i-AmAc over Amberlite IR-120 is proposed in this paper. Figure 2 shows the structure of the CRD process. i-AmAc product purity specification is set at $97 \pm 0.5$ mole $\%$ i-AmAc with no more than 0.1 acidity (equals to around $<0.15$ mass $\%$ HAc).

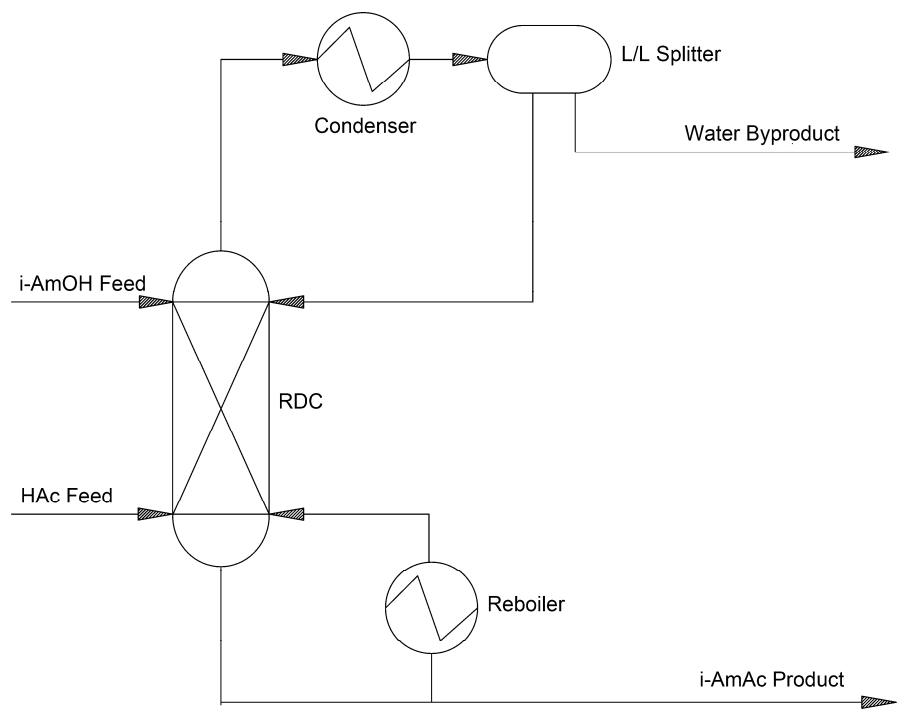

Figure 2. CRD process for synthesis of i-AmAc

HAc feed stream and $\mathrm{i}-\mathrm{AmOH}$ feed stream are fed to the reactive distillation column with a $\mathrm{L} / \mathrm{L}$ phase splitter set at the top of the column separately. From Figure 1, the liquid phase separation area will significantly decrease with the increase of HAc mole fraction. To ensure the occurrence of phase separation at the L/L phase splitter, . the mole feed ratio of $\mathrm{i}-\mathrm{AmOH} / \mathrm{HAc}$ was set as 1.05:1 in this process to guarantee the complete reaction of HAc. Such feed ratio setting also decrease the acidity in i-AmAc product, which is one of the specification of the final product. The vapor distillate stream from the top of the column is transported into the $\mathrm{L} / \mathrm{L}$ phase splitter after totally condensed. Such distillate stream with less than 1 mole \% of HAc and i-AmAc is marked as purple points in Figure 1. According to the two-liquid-phase area in Figure 1, the totally condensed stream is split into two phases in L/L phase splitter. The organic-phase stream is refluxed and fed to the top of the column, and the water- 
phase stream with $97.5 \mathrm{~mol} \%$ water is pumped out as a byproduct. Product stream containing $97 \mathrm{~mol} \% \mathrm{i}$-AmAc with no more than 0.15 mass $\%$ HAc is obtained from the bottom of the column. The i-AmOH feed stream is fed above the HAc feed stream. The pressure of the CRD column $\left(\mathrm{P}_{\mathrm{CRD}}\right)$ is fixed at $1 \mathrm{~atm}(101.325 \mathrm{kPa})$; the pressure drop of the condenser is assumed to be $2 \mathrm{kPa}$; the tray pressure drop is assumed to be $600 \mathrm{~Pa}[11,16,17]$.

\subsection{DPTCRD process}

The structure of DPTCRD process for synthesis of i-AmAc over Amberlite IR-120 is shown in Figure 3.

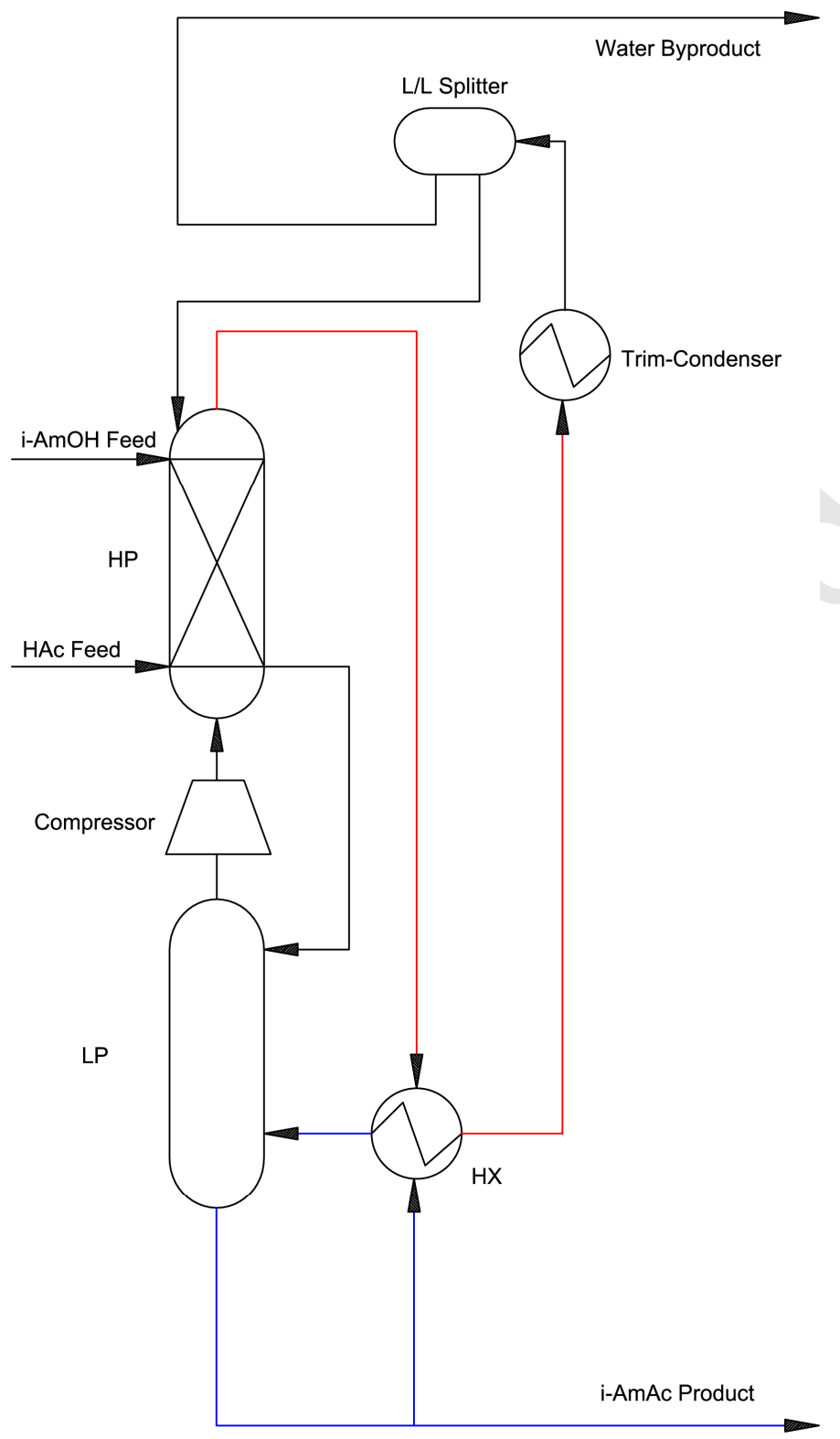


Figure 3. DPTCRD process for synthesis of i-AmAc

Two columns with different operation pressure are included in the DPTCRD process, which are named as highpressure (HP) column and low-pressure (LP) column, respectively. The reaction section is set in the HP column with catalyzer on the trays, and $\mathrm{i}-\mathrm{AmOH}$ feed stream and HAc feed stream are fed to the HP column. Liquid outflow of the last tray of the HP column is fed to the top of the LP column, while the vapor of the first tray of the LP column is fed to the bottom of the HP column via a compressor. Since the top pressure of the HP column is much higher than that of the LP column, the top temperature of the HP column is thus higher than the bottom temperature of the LP column. Therefore, the energy of the top stream of the HP column could be reused by transporting to the reboiler of the LP column as heat source. A trim condenser is added to the outlet side of the HP column top stream from the reboiler to ensure the complete condensation. The condensed stream is then transported into a L/L phase splitter. The organic-phase stream is refluxed and fed to the top of the HP column, and the water-phase stream with $97.5 \mathrm{~mol} \%$ water is pumped out as a byproduct. The product stream containing 97 mol \% i-AmAc with no more than 0.15 mass \% HAc is obtained from the bottom of the LP column. The pressure of the HP column ( $\left.\mathrm{P}_{\mathrm{HP}}\right)$ is fixed at $1 \mathrm{~atm}(101.325 \mathrm{kPa})$; the pressure drop of the condenser is assumed to be $2 \mathrm{kPa}$; the tray pressure drop of the HP column is assumed to be $600 \mathrm{~Pa}$; the tray pressure drop of the LP column is assumed to be $200 \mathrm{~Pa}$.

\section{Economical Optimization}

To evaluate the economic feasibility of the DPTCRD process and the CRD process, several variables need to be determined. For the optimization of the DPTCRD process, variables need to be determined are as follows: the number of trays in the HP column $\left(\mathrm{N}_{\mathrm{HP}}\right)$ and the LP column $\left(\mathrm{N}_{\mathrm{LP}}\right)$; the number of trays in reaction section $\left(\mathrm{N}_{\mathrm{R}}\right)$; 
the first tray of reaction section $\left(\mathrm{N}_{F R}\right)$; and the feed position of $\mathrm{i}-\mathrm{AmOH}\left(\mathrm{N}_{\mathrm{F} 1}\right)$ and HAc $\left(\mathrm{N}_{\mathrm{F} 2}\right)$. Since the HP column has a phase-split-reflux structure, the reflux ratio of the HP column is uncontrollable, and thus only the reflux ratio of the LP column $\left(\mathrm{R}_{\mathrm{LP}}\right)$ need to be determined. For the optimization of the CRD process, the variables which need to be determined include the number of trays $\left(\mathrm{N}_{\mathrm{CRD}}\right)$, the number of trays in reaction section $\left(\mathrm{N}_{C R}\right)$, the first tray of reaction section $\left(\mathrm{N}_{\mathrm{FCR}}\right)$, the feed position of $\mathrm{i}-\mathrm{AmOH}\left(\mathrm{N}_{\mathrm{CF} 1}\right)$ and $\mathrm{HAc}\left(\mathrm{N}_{\mathrm{CF} 2}\right)$, and the reboiler ratio $\left(\mathrm{R}_{\mathrm{CRD}}\right)$.

\subsection{Sensitivity Analysis}

DPTCRD process operates two columns under different pressure and achieve heat-integration via the temperature difference between the columns, which means the selection of column pressure is of great importance. On the other hand, the column pressures also have an influence on product purity and heatexchanger/compressor duties. In the DPTCRD process, the HP column was designed to be operated under standard atmospheric pressure $(101.325 \mathrm{kPa})$, and the top pressure of the LP column ( $\left.\mathrm{P}_{\mathrm{LP}}\right)$ was thus need to be determined. In sensitivity analysis, the top pressure of the LP column was varied from 0.100 to 0.350 bar, and the variation trend of product purity, top temperature of the HP column, bottom temperature of the LP column, compressor duty, condenser duty and reboiler duty were studied as shown in Figure 4. 
(a)
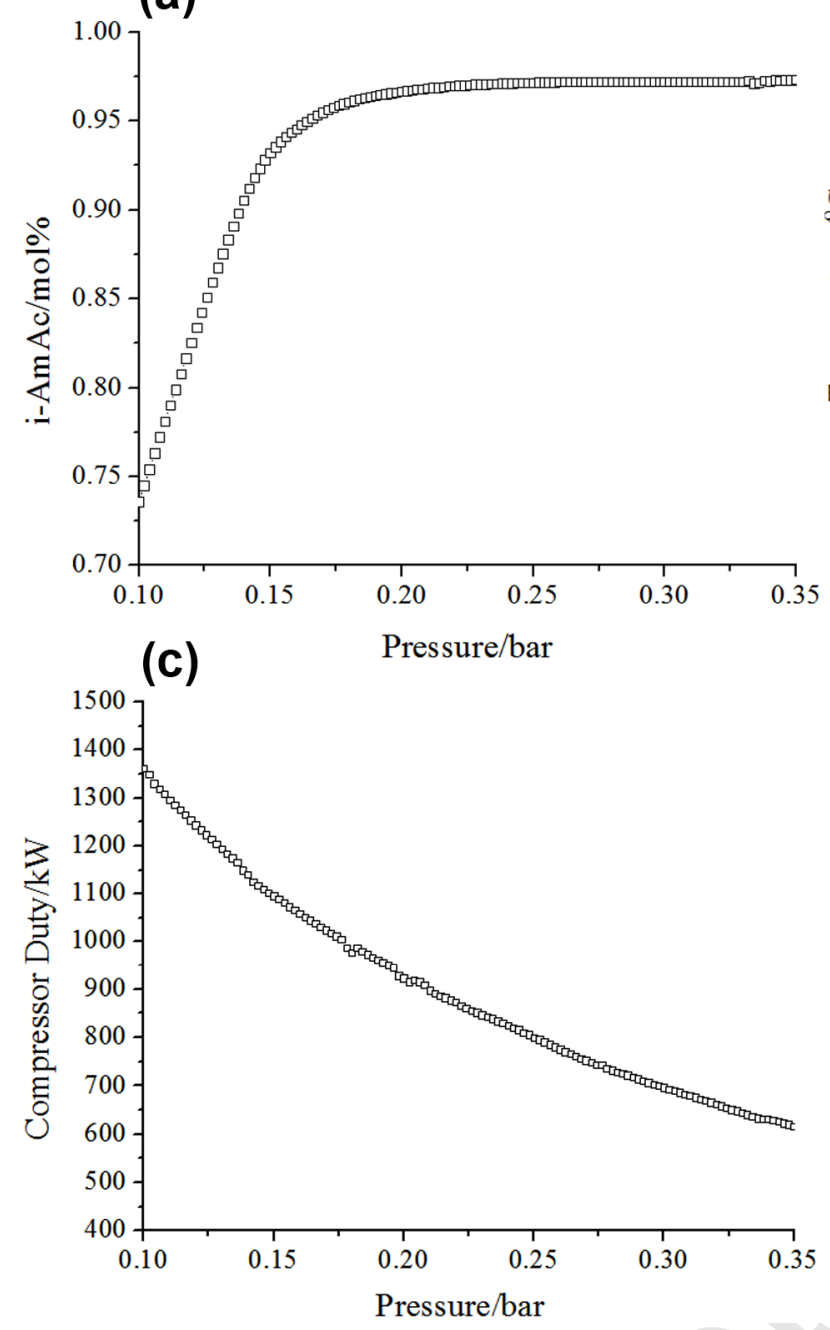

(b)
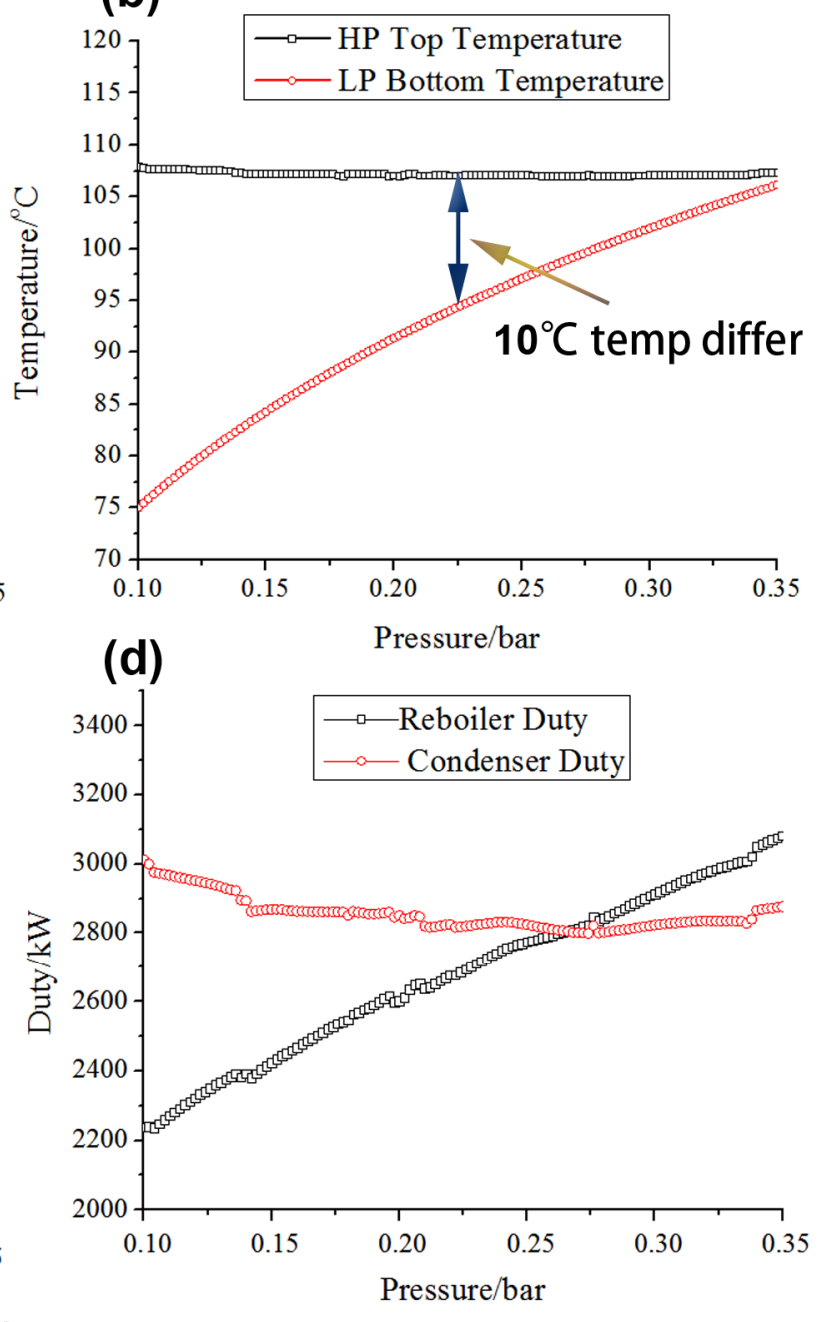

Figure 4. Effects of pressure of LP column on (a) i-AmAc mole fraction in i-AmAc product (b) HP top temperature and LP bottom temperature (c) compressor duty (d) reboiler and condenser duty

The product purity can reach the specification when LP column top pressure is above 0.200 bar. Since the heatintegration structure is not constructed directly in Aspen Plus, the duty of the trim condenser is calculated by the difference between the condenser duty and the reboiler duty. In Figure 4, both the trim condenser duty and the compressor duty decrease with the increase of the LP column top pressure until it reaches 0.264 bar, which means the top pressure of the LP column should be determined as high as possible to achieve more energy consumption. 
The minimum heat transfer temperature difference was set as $10{ }^{\circ} \mathrm{C}$ in this paper, thus the difference between the top temperature of the HP column and the bottom temperature of the LP column limited the pressure. It could be seen that as the top pressure of the LP column increases from 0.100 to 0.350 bar, the top temperature of the HP column does not show apparently variation, and the bottom temperature of the LP column rises from 75.01 ${ }^{\circ} \mathrm{C}$ to $106.14{ }^{\circ} \mathrm{C}$. Since the fluctuation in control may change the process temperature, the temperature difference is not set at exactly $10{ }^{\circ} \mathrm{C}$, an allowance should be considered. Finally, 0.224 bar was selected as the top pressure of the LP column.

\subsection{Process Optimization}

Process optimization was applied to the DPTCRD process. Since there were several variables need to be determined in this process, a sequential iterative optimization procedure was used to determine the values. The optimization procedure was based on the research of Li et al. [15], $\mathrm{N}_{H P}, \mathrm{~N}_{L P}, \mathrm{~N}_{\mathrm{R}}, \mathrm{N}_{\mathrm{FR}}$ were set as outer iterative loop, $\mathrm{N}_{\mathrm{F} 1}, \mathrm{~N}_{\mathrm{F} 2}$ were set as inner iterative loop, and the whole optimization process is shown in Figure 5.

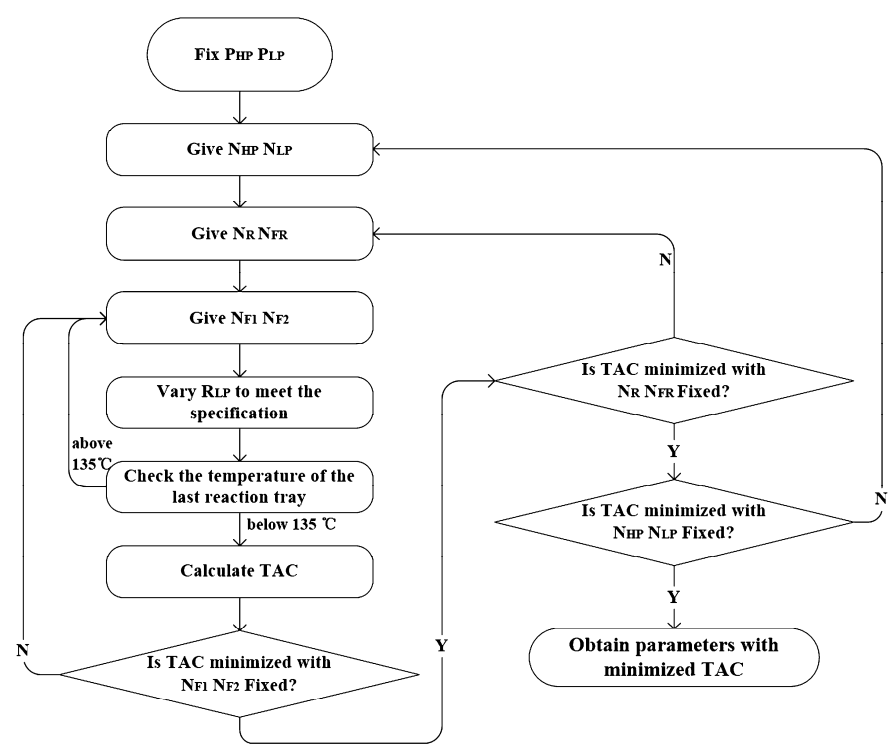

Figure 5. Optimization process of the DPTCRD 
Minimized total annual cost (TAC) is the target of the optimization, and the calculation of TAC can be described as expression (4).

$\mathrm{TAC}=\mathrm{OC}+\mathrm{CI} / T$

where $\mathrm{OC}$ is the operation cost, $\mathrm{CI}$ is the capital investment, and $T$ is the payback period. In this paper, 5 years was chosen as the payback period. CI included the cost of columns, heat-exchanger and compressor. The size of column was calculated by Tray Sizing option in Aspen Plus, and the tray spacing was set as $0.6096 \mathrm{~m}$. Equations for the CI calculation were based on research of Douglas [18], which were provided in the supporting files. OC included the cost of cooling water, catalyzer, electricity and steam, and there was no steam to use in the DPTCRD process due to the heat-integrated structure. $8000 \mathrm{~h} /$ year was presumed to be the processing time in OC calculation, and the utility price were taken from relevant papers [19,20], which were also provided in the supporting files. The Marshall \& Swift index which was used in TAC calculation is specified at 1468.2 [21].

To certify the energy-saving effect of DPTCRD, the CRD process was also optimized as a contrast. Another sequential iterative optimization procedure was used to determine the values, as shown in Figure 6. $\mathrm{N}_{\mathrm{CRD}}, \mathrm{N}_{\mathrm{CR}}$, $\mathrm{N}_{\mathrm{CFR}}$ were set as outer iterative loop, $\mathrm{N}_{\mathrm{CF} 1}, \mathrm{~N}_{\mathrm{CF} 2}$ were set as inner iterative loop. The method of TAC calculation has been provided in expression (4), and the detailed equations for TAC calculation are also provided in the supporting files based on the research of Douglas [18]. 


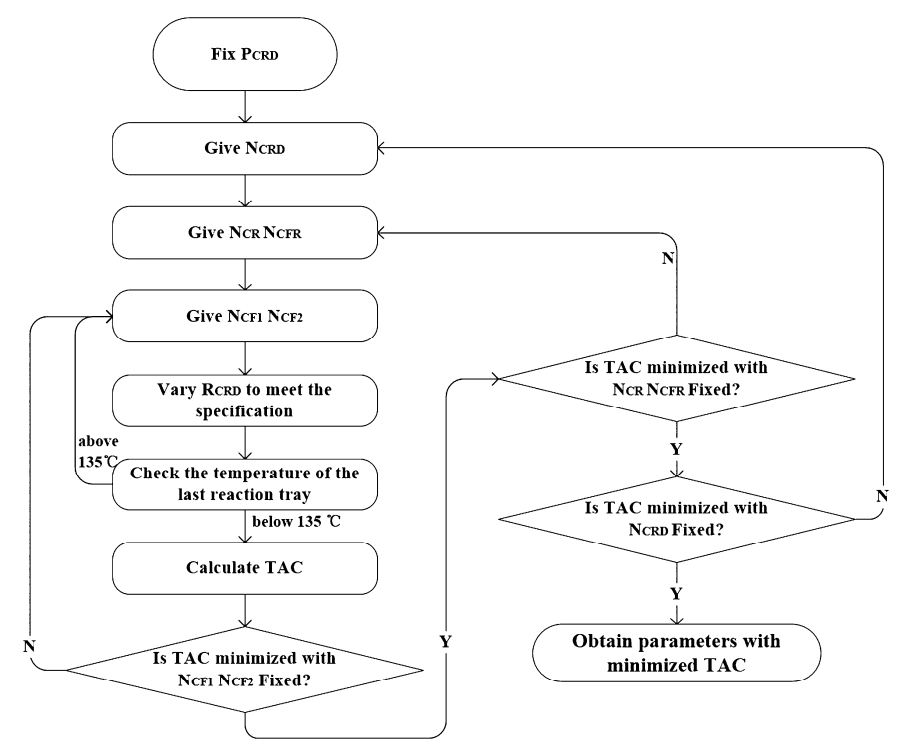

Figure 6. Optimization process of the CRD

\subsection{Process Optimization Results and Comparison}

The effect of key parameters on TAC and product purity of the two processes were shown in Figure 7 and

Figure 8, and the overall optimization results with other important operating parameters for the DPTCRD process and the CRD process have been listed in Table 2. 

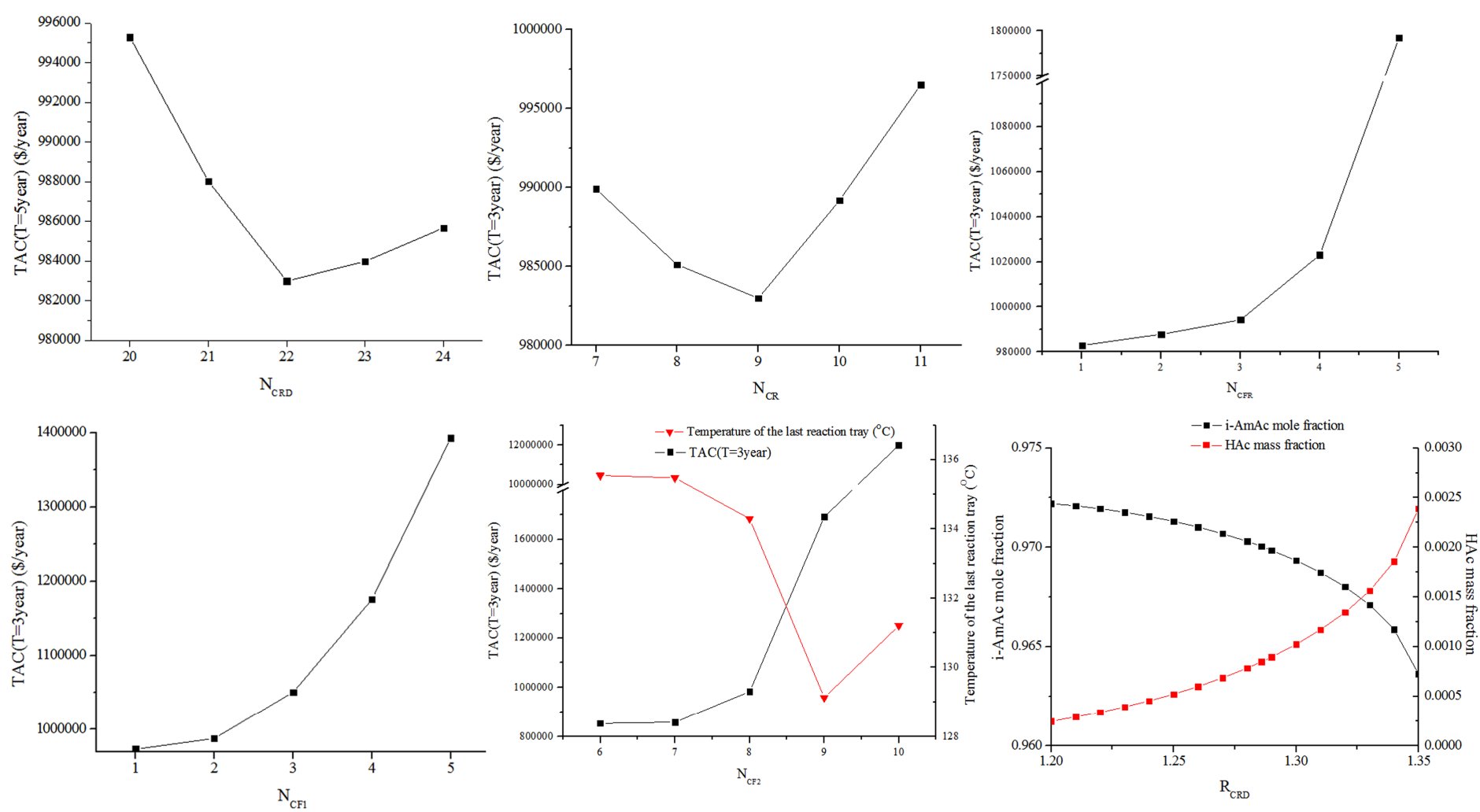

Figure 7. Effect of $\mathrm{N}_{\mathrm{CRD}}, \mathrm{N}_{\mathrm{CR}}, \mathrm{N}_{\mathrm{CFR}}, \mathrm{N}_{\mathrm{CF} 1}, \mathrm{~N}_{\mathrm{CF} 2}$ on $\mathrm{TAC}$, and of $\mathrm{R}_{\mathrm{CRD}}$ on product purity. 

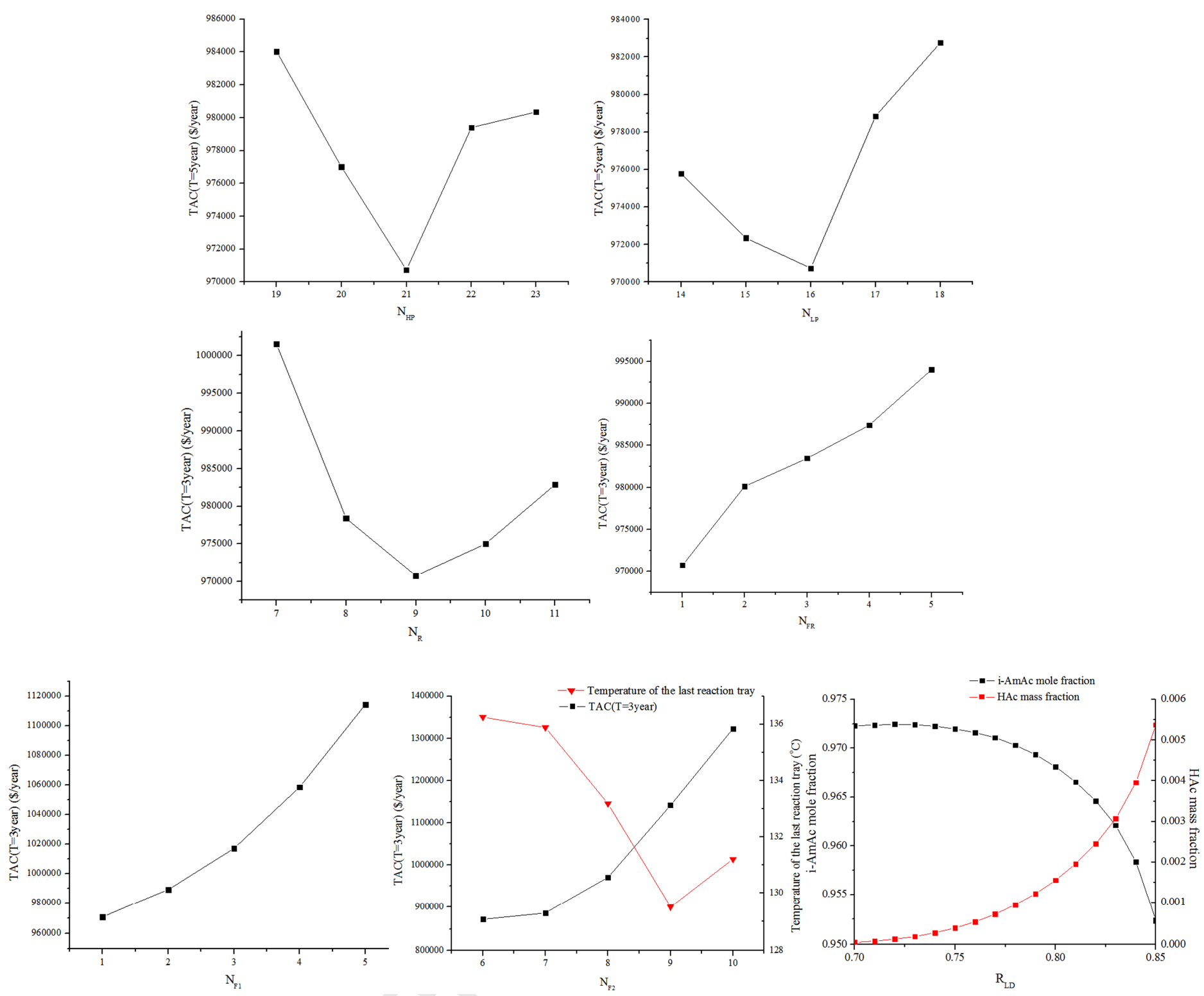

Figure 8. Effect of $\mathrm{N}_{H P}, \mathrm{~N}_{\mathrm{LP}}, \mathrm{N}_{\mathrm{R}}, \mathrm{N}_{\mathrm{FR}}, \mathrm{N}_{\mathrm{F} 1}, \mathrm{~N}_{\mathrm{F} 2}$ on $\mathrm{TAC}$, and of $\mathrm{R}_{\mathrm{LD}}$ on product purity.

The parameters that should be firstly decided is the number of trays $\left(\mathrm{N}_{\mathrm{CRD}}, \mathrm{N}_{\mathrm{HP}}, \mathrm{N}_{\mathrm{LP}}\right)$. With the increase of number of trays, the reflux ratio decreases, which means smaller diameter can be chosen for the columns. Such variation leads the decrease of reboiler and condenser duty. But due to the increase of column height, whether the capital investment will decrease or not need to be calculated. For DPTCRD process, the increase of number of trays leads a smaller temperature difference between the top of the HP column and the bottom of the LP column, 
which means higher demand for the vacuum degree of the LP column. Such variation leads the increase of compressor power, and may finally leads the increase of total operation cost.

Before the study of the influence of number of reaction trays $\left(\mathrm{N}_{\mathrm{CR}}, \mathrm{N}_{\mathrm{R}}\right)$, feed position $\left(\mathrm{N}_{\mathrm{F} 1}, \mathrm{~N}_{\mathrm{F} 2}, \mathrm{~N}_{\mathrm{CF} 1}\right.$ and $\left.\mathrm{N}_{\mathrm{CF} 2}\right)$ and first tray of reaction section $\left(\mathrm{N}_{\mathrm{FR}}, \mathrm{N}_{\mathrm{CFR}}\right)$ on $\mathrm{TAC}$, an important limitation of maximum operation temperature should be considered and obeyed. The maximum operation temperature of IR-120 is $135^{\circ} \mathrm{C}$ [12], and with the variation of the parameters mentioned above, the temperature of the reaction section may increase. If the temperature of the last reaction tray is over $135^{\circ} \mathrm{C}$, other measures should be applied to the process to decrease the temperature of the reaction trays.

The number of reaction tray $\left(\mathrm{N}_{\mathrm{CR}}, \mathrm{N}_{\mathrm{R}}\right)$ has dual influences on TAC. With the increase of reaction trays, the reactive holdup increases, which means the decrease of separation requirement, and finally leads the decrease of reboiler/condenser duty. While, if the consumption of reboiler/condenser duty cannot counteract the increase of catalyst cost, the operation cost will increase, instead of decrease. On the other hand, if the number of reaction tray changes with feed position fixed, the relative position of the feed will change, which may lead the temperature change in reaction section, and such behavior also occurs when $\mathrm{N}_{F R}$ and $\mathrm{N}_{\mathrm{CFR}}$ change. In the processes of this paper, the temperature of last reaction tray increases with the upward displacement of $\mathrm{N}_{F 2} / \mathrm{N}_{\mathrm{CF} 2}$ (with other parameters fixed). This is because the variation of feed position leads the change of composition on trays, and increased heavy components lead a temperature increase on reaction trays. On the other hand, the relative feed position change increases the mole fraction of HAc on reaction trays below the feed. Considering the $\mathrm{i}-\mathrm{AmOH}$ feed is excess, the HAc mole fraction in the whole system remains a low level. The increased HAc on nearby trays of the HAc feed accelerates the esterification reaction, which leads the decrease of TAC. Based on the 
reasons above, feed position is thus varied to decrease the tray temperatures in the optimization of $N_{C R}, N_{R}, N_{F R}$ and $\mathrm{N}_{\mathrm{CFR}}$, and the TAC is recalculated in this case. The recalculated TAC results are provided in the figures. The temperature limitation of the reaction trays restricts the design of the processes. In the optimization of $\mathrm{N}_{\mathrm{F} 2} / \mathrm{N}_{\mathrm{CF} 2}$, since there are no other methods to decrease the temperature effectively(the pressure of $\mathrm{CRD} / \mathrm{HP}$ are fixed at 101.325 $\mathrm{kPa}$ ), both the $\mathrm{N}_{\mathrm{F} 2} / \mathrm{N}_{\mathrm{CF} 2}$ are fixed at 8 , which can provide lowest TAC with acceptable temperature.

The lowest point which provides minimum TAC for the two process with fixed parameters $\left(\mathrm{N}_{\mathrm{CRD}}, \mathrm{N}_{\mathrm{CR}}, \mathrm{N}_{\mathrm{CFR}}\right.$, $\mathrm{N}_{\mathrm{CF} 1}$ and $\mathrm{N}_{\mathrm{CF} 2}$ for the CRD process, $\mathrm{N}_{\mathrm{HP}}, \mathrm{N}_{\mathrm{LP}}, \mathrm{N}_{\mathrm{R}}, \mathrm{N}_{\mathrm{FR}}, \mathrm{N}_{\mathrm{F} 1}$ and $\mathrm{N}_{\mathrm{F} 2}$ for the DPTCRD process) could be found in Figure 7 and Figure 8, and the reflux ratios which were varied to reach the product purity for each change of the parameters in optimization.

The results in Table 2 indicate that the DPTCRD process shows $39.65 \%$ saving on operating cost, and $1.25 \%$ saving on TAC with 5-year payback period. Considering the operating cost of the DPTCRD is much lower than the CRD cost, TAC cost saving of the DPTCRD process will be more obvious when the payback period is set longer. Figure 9 shows the TAC variation of the DPTCRD and the CRD process when the payback period varied from 1 to 10 years. It reveals that the TAC of the DPTCRD process is lower than that of the CRD process when the payback period is set as 5 years or more, and the DPTCRD process can reach a $19.05 \%$ saving on TAC when payback period is set as 10 years.

Table 2. Operating parameters for the DPTCRD process and the CRD process

\begin{tabular}{llll}
\hline Parameters & CRD & DPTCRD & \\
& & HP & LP \\
\hline number of trays & 22 & 21 & 16 \\
column diameter $(\mathrm{m})$ & 1.87 & 2.01 & 2.26
\end{tabular}




\begin{tabular}{|c|c|c|c|}
\hline column height(m) & 19.05 & 19.46 & 14.79 \\
\hline reactive trays & $1 \sim 9$ & $1 \sim 9$ & \\
\hline HAc feed flowrate $(\mathrm{kmol} / \mathrm{hr})$ & 100 & 100 & \\
\hline HAc feed tray & 8 & 8 & \\
\hline $\mathrm{i}-\mathrm{AmOH}$ feed flowrate $(\mathrm{kmol} / \mathrm{hr})$ & 105 & 105 & \\
\hline $\mathrm{i}-\mathrm{AmOH}$ feed tray & 1 & 1 & \\
\hline mole reflux ratio & 1.29 & 1.23 & 0.78 \\
\hline top pressure $(\mathrm{kPa})$ & 101.325 & 101.325 & 22.4 \\
\hline condenser duty $(\mathrm{kW})$ & -2283 & -2768 & \\
\hline reboiler duty $(\mathrm{kW})$ & 3453 & & וכנ \\
\hline compressor duty(kW) & & 844 & \\
\hline capital investment(\$) & 666313 & 2289438 & \\
\hline operating $\operatorname{cost}(\$ /$ year $)$ & 849733 & 512850 & \\
\hline TAC ( $\$ /$ year $) \mathrm{T}=5$ year & 982995 & 970737 & \\
\hline
\end{tabular}

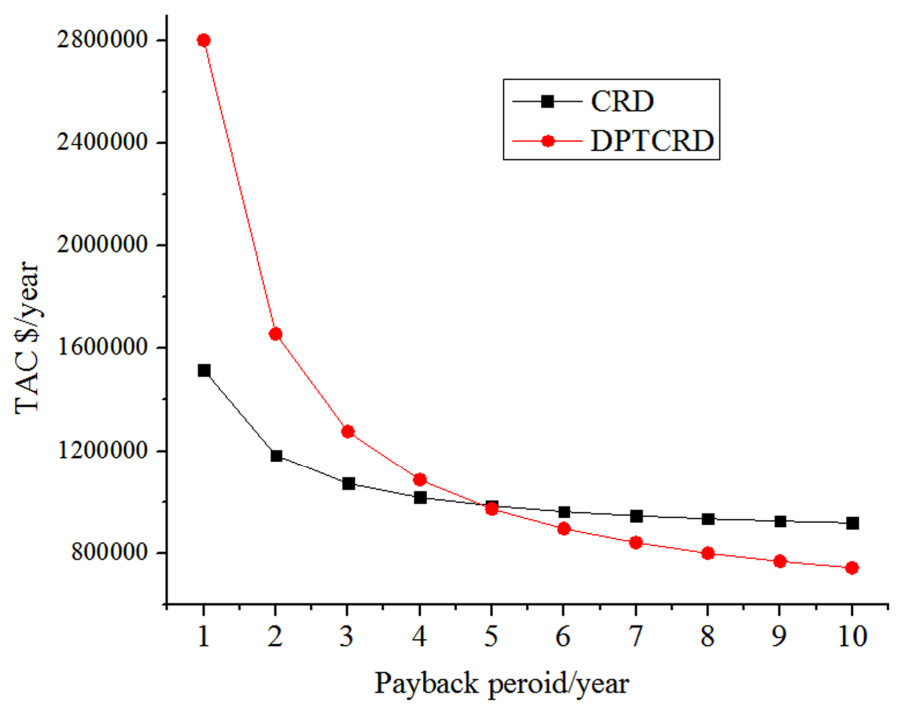


Figure 9. TAC variation of the DPTCRD and the CRD process

The column composition and temperature profiles of the CRD and the DPTCRD processes are provided in

Figure 10 and Figure 11 respectively, and both the vapor and liquid composition profiles are revealed. It can be seen from the figures that the composition variation trend of the CRD and the DPTCRD process is quite similar, while the temperature profiles show differences. The CRD process shows large temperature differs at $1^{\text {st }}$ and $8^{\text {th }}$ tray due to the feed of $\mathrm{i}-\mathrm{AmOH}$ and HAc, respectively, while in the DPTCRD process a sharp temperature decrease could be found at the top of the LP column because of the pressure difference between the HP column and LP column, which provides the basis for the design of heat-integration structure.

(a)
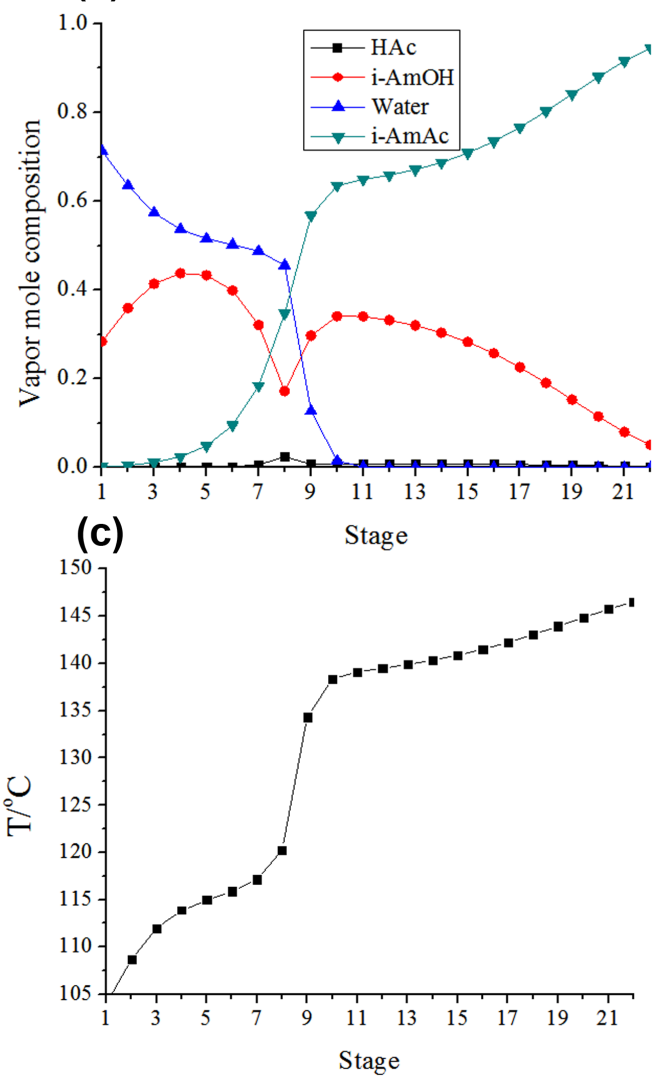

(b)

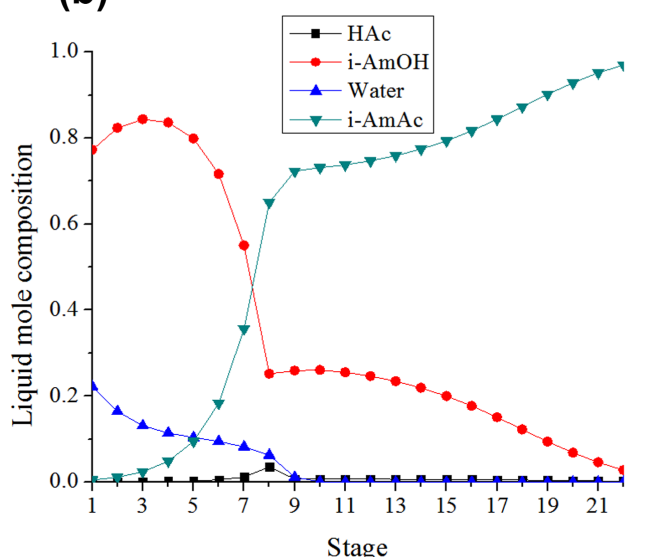

Figure 10. Profiles of CRD (a) vapor composition (b) liquid composition (c) temperature 
(a)

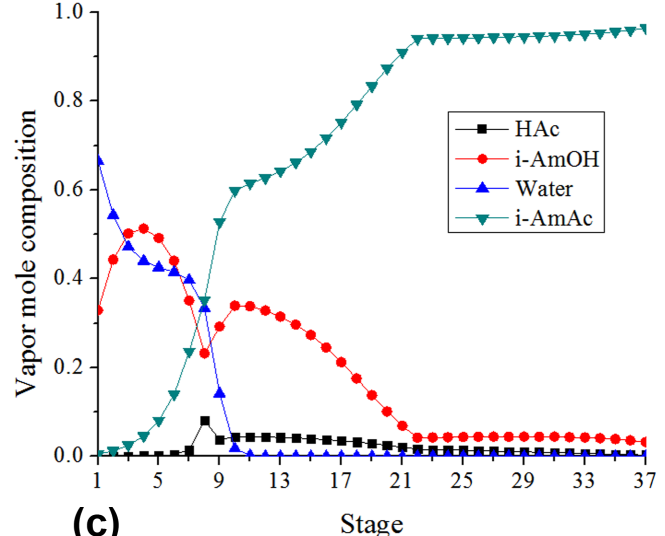

(c)

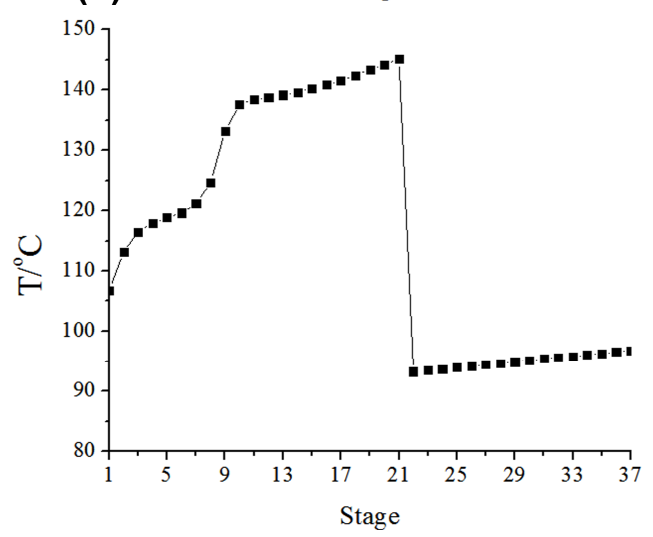

(b)

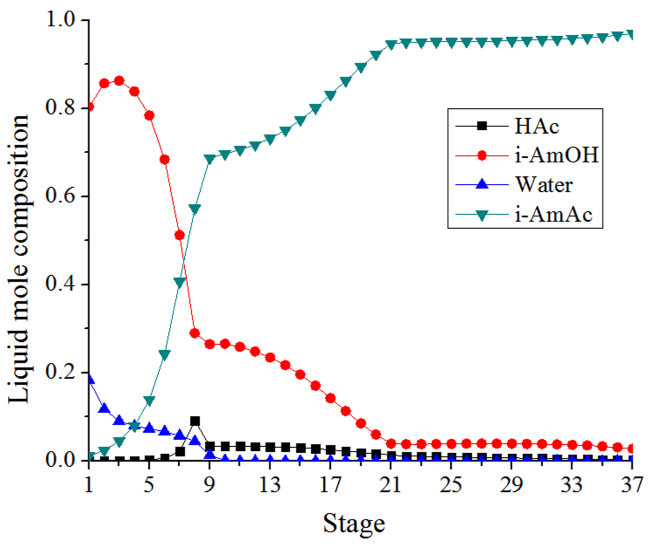

Figure 11. Profiles of DPTCRD (a) vapor composition (b) liquid composition (c) temperature

\section{Control Structure Design}

The DPTCRD process with optimized parameters was imported into Aspen Dynamics to research the controllability. In Aspen Dynamics, plantwide control schemes were considered for the process, and the control behaviors were studied. Based on the control behaviors, two improved control structures were proposed to improve the controllability.

\subsection{Basic control structure (BC)}




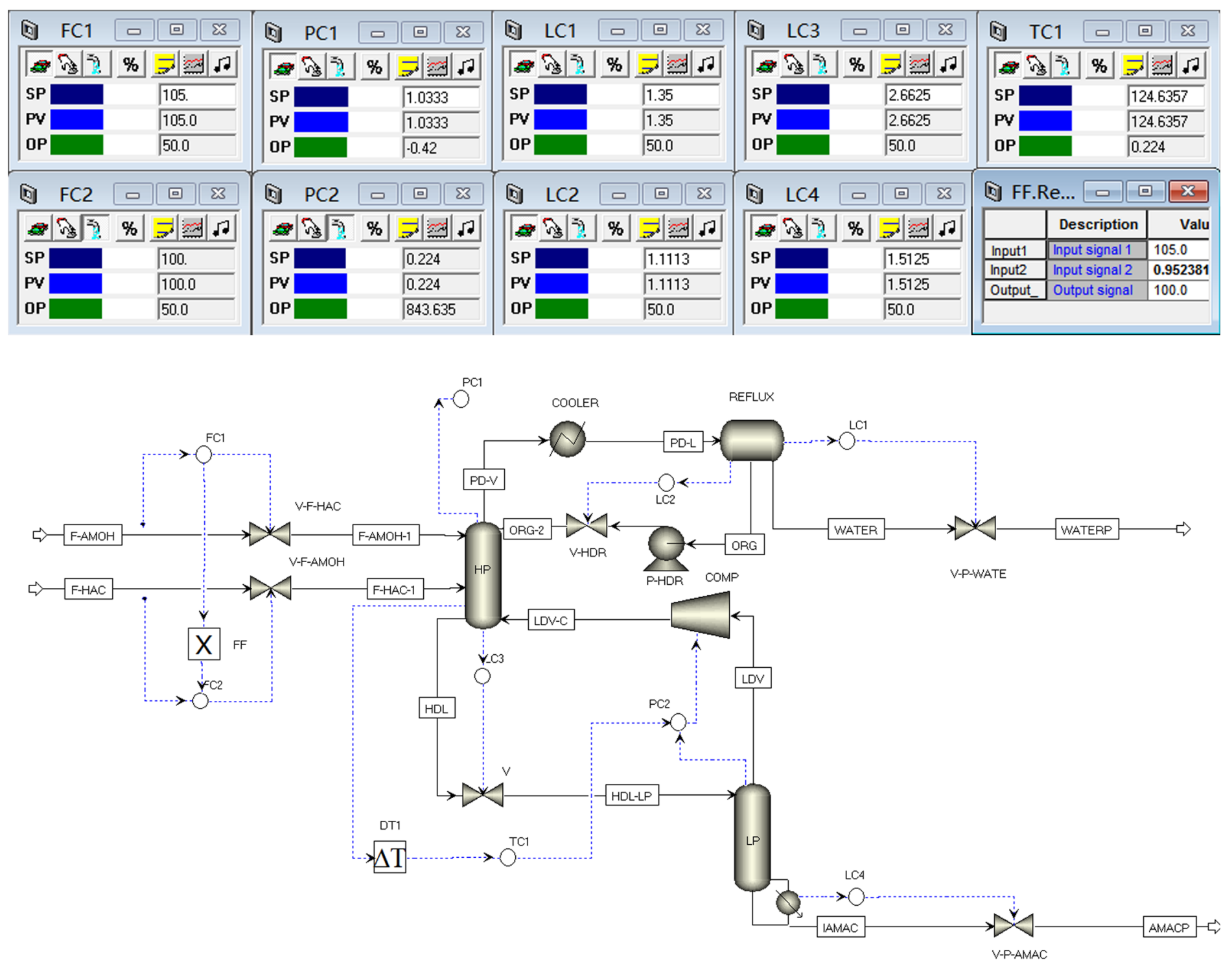

Figure 12. Basic control structure (BC) for the DPTCRD process

The basic structure is shown in Figure 12. Each feed stream was controlled with a feed flowrate controller separately. A feed ratio controller was added to the feed flowrate controllers to keep the feed mole ratio of i$\mathrm{AMOH} / \mathrm{HAc}$ at 1.05:1. Liquid level of columns and the two-phase splitter were controlled with liquid level controllers, and thus two liquid level controllers were installed on the liquid/liquid two-phase splitter to control the two liquid levels separately. Pressure controllers were applied to the columns to control the top pressure, and 
the top pressure of the LP column was controlled by the brakepower of the compressor and the top pressure of the HP column was controlled by the duty of the trim condenser. Since the initial model did not include the heatintegrated structure, the actual trim condenser duty is calculated by expressions [15], which can be described as expression (5) and expression (6):

$Q_{\mathrm{R}, \mathrm{LP}}=\mathrm{UA}\left(T_{\mathrm{R}, \mathrm{HP}}-T_{\mathrm{B}, \mathrm{LP}}\right)$

$Q_{\mathrm{C}, \mathrm{HP}}=-Q_{\mathrm{A}, \mathrm{HP}}-Q_{\mathrm{R}, \mathrm{LP}}$

where $Q_{\mathrm{R}, \mathrm{LP}}$ means the reboiler duty of the LP column, $Q_{\mathrm{C}, \mathrm{HP}}$ and $Q_{\mathrm{A}, \mathrm{HP}}$ are the condenser and the trim condenser duty of the HP column, respectively. UA [9] is overall heat transfer coefficient which calculated by initial temperature difference and reboiler duty of the LP column, and $T_{\mathrm{R}, \mathrm{HP}}$ and $T_{\mathrm{B}, \mathrm{LP}}$ are the top and the bottom temperatures of the HP and the LP column, respectively.

The two expressions were imported into Aspen Dynamics as shown in Figure 13, the condenser duty of the HP column and the reboiler duty of the LP column were set to "free".

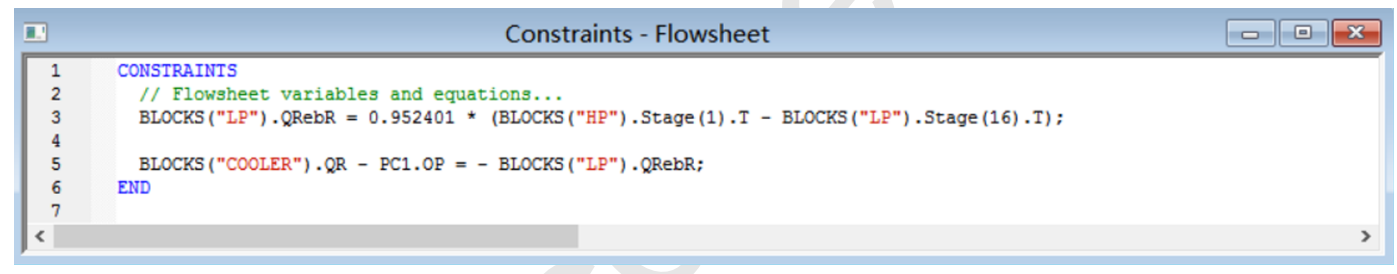

Figure 13. Heat integration equations implemented in Aspen Dynamics

A temperature controller with a dead time module of $1 \mathrm{~min}$ was applied on the i-AmAc product stream to control the column temperature. To add a temperature controller to the system, the sensitive tray was researched and selected based on open-loop sensitivity analysis as shown in Figure 14[15]. 


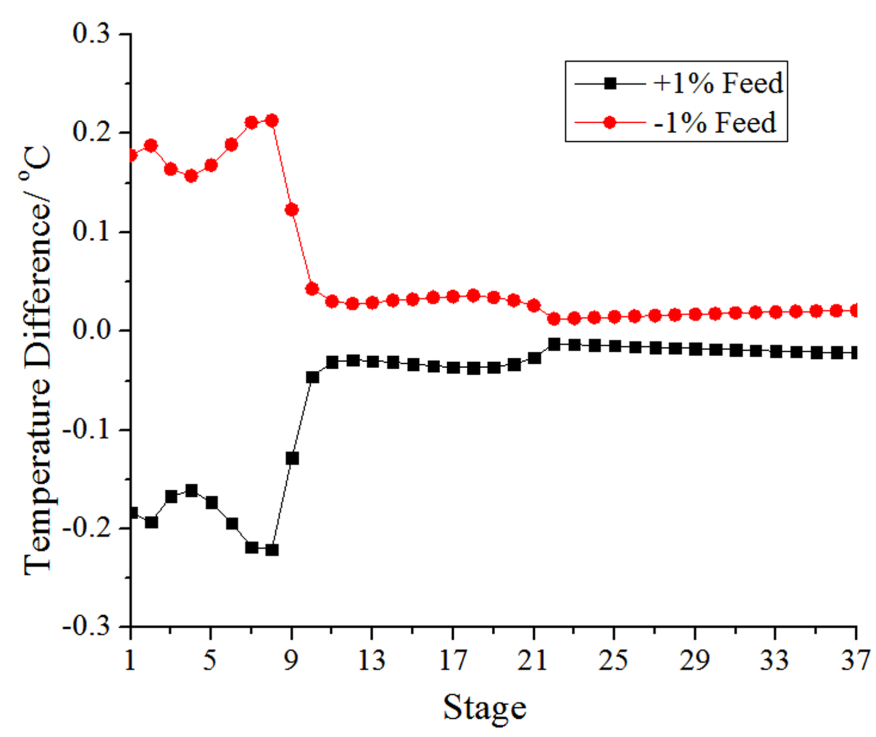

Figure 14. Sensitive tray analysis

Figure 14 reveals that the $8^{\text {th }}$ tray of the HP column had a largest temperature difference, which was finally selected as the sensitive tray. A temperature controller was installed at the $8^{\text {th }}$ tray of the HP column. Considering the tray temperature can be influenced by the compressor via the vapor feed stream below the last tray of the HP column, the control output was connected to the pressure controller of the LP column on cascade, which had a direct influence on the brakepower of the compressor.

Determination of the tuning parameters of the controllers were based on the research of Luyben [15]. All the flowrate controllers were set with the gain $\mathrm{K}_{\mathrm{C}}=0.5$, and the integral time $\tau_{\mathrm{I}}=0.3 \mathrm{~min}$. All the liquid level controllers were set with the gain $\mathrm{K}_{\mathrm{C}}=2$, and the integral time $\tau_{\mathrm{I}}=9999 \mathrm{~min}$. All the pressure controllers were set with the gain $\mathrm{K}_{\mathrm{C}}=20$, and the integral time $\tau_{\mathrm{I}}=12 \mathrm{~min}$. The tuning parameter of the temperature controller is determined by Tyreus-Luyben tuning settings, and was set with the gain $\mathrm{K}_{\mathrm{C}}=11.8$, and the integral time $\tau_{\mathrm{I}}=$ $3.96 \mathrm{~min}$. The process was run steadily and then a $\pm 10 \%$ disturbance of $\mathrm{i}-\mathrm{AmOH}$ feed flowrate was introduced to the system. Considering that HAc and water can be solute with each other at any proportion, a $+10 \%$ 
disturbance of water composition in HAc feed stream was also introduced to the system. The water composition disturbance of $\mathrm{i}-\mathrm{AmOH}$ feed was neglected in the control behavior analysis, since most of the water can be removed by a $\mathrm{L} / \mathrm{L}$ phase splitter in industrial application if water was mixed into $\mathrm{i}-\mathrm{AmOH}$ feed.

(a)
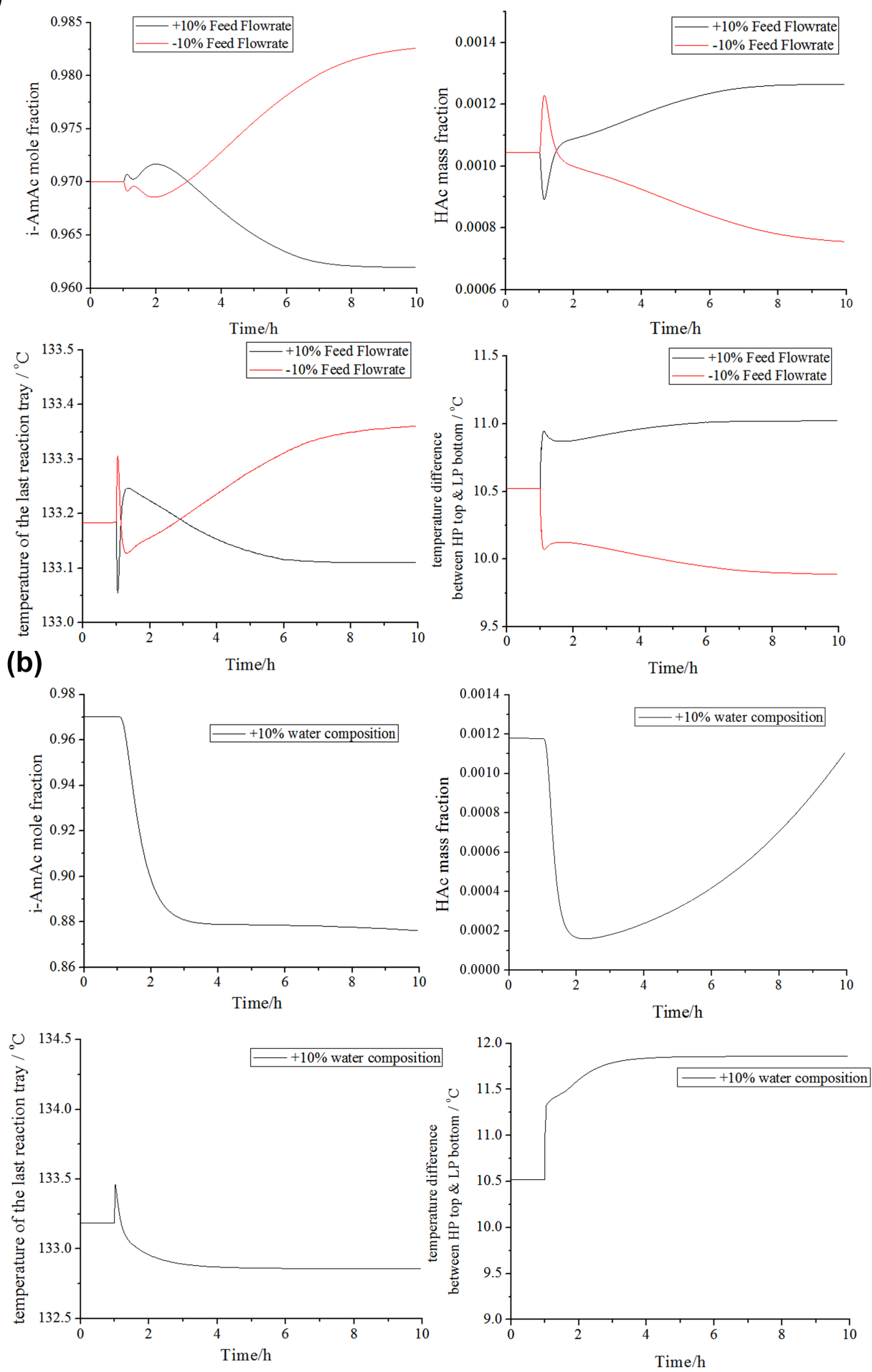
Figure 15. Control behaviors of the BC structure (a) with $\pm 10 \%$ disturbance of $\mathrm{i}-\mathrm{AmOH}$ feed flowrate (b) with $+10 \%$ disturbance of water composition in HAc feed stream

Figure 15 shows the control behaviors of the basic control structure. The product purity can reach new stable values within 7 hours with feed flowrate disturbance, while the HAc mass fraction could not reach a new stable point, the temperature difference reaches the minimum limit of $10{ }^{\circ} \mathrm{C}$ and the residual error of both the fraction of i-AmAc and HAc under the disturbance of feed flowrate or water composition are not acceptable, which mean the structure need to be improved.

\subsection{Improved Control Structure 1 (IC1)}

Since using the temperature controller independently could not provide dependable control behaviors, a composition controller was considered. The composition controller was applied on the i-AmAc product stream to control the $\mathrm{i}-\mathrm{AmAc}$ mole fraction $(\mathrm{CC} 1)[22,23]$. A dead time module with $3 \mathrm{~min}$ is added to the composition controller. Since the feed ratio had a significant influence on the product purity by the percentage of unreacted i$\mathrm{AmOH}$, the control output of the composition controller was connected to the feed ratio controller on cascade as shown in Figure 16.

The tuning parameter of the composition controller is determined by Tyreus-Luyben tuning settings and was set with the gain $\mathrm{K}_{\mathrm{C}}=12.12$, and the integral time $\tau_{\mathrm{I}}=201 \mathrm{~min}$. The output range of the composition controller is set as $0.8 \sim 1.1$ to prevent from unstable. $\mathrm{A} \pm 10 \%$ disturbance of $\mathrm{i}-\mathrm{AmOH}$ feed flowrate and a $+10 \%$ disturbance of water composition in HAc feed stream was then introduced to the system to research the controllability, and the control behaviors were shown in Figure 17. 


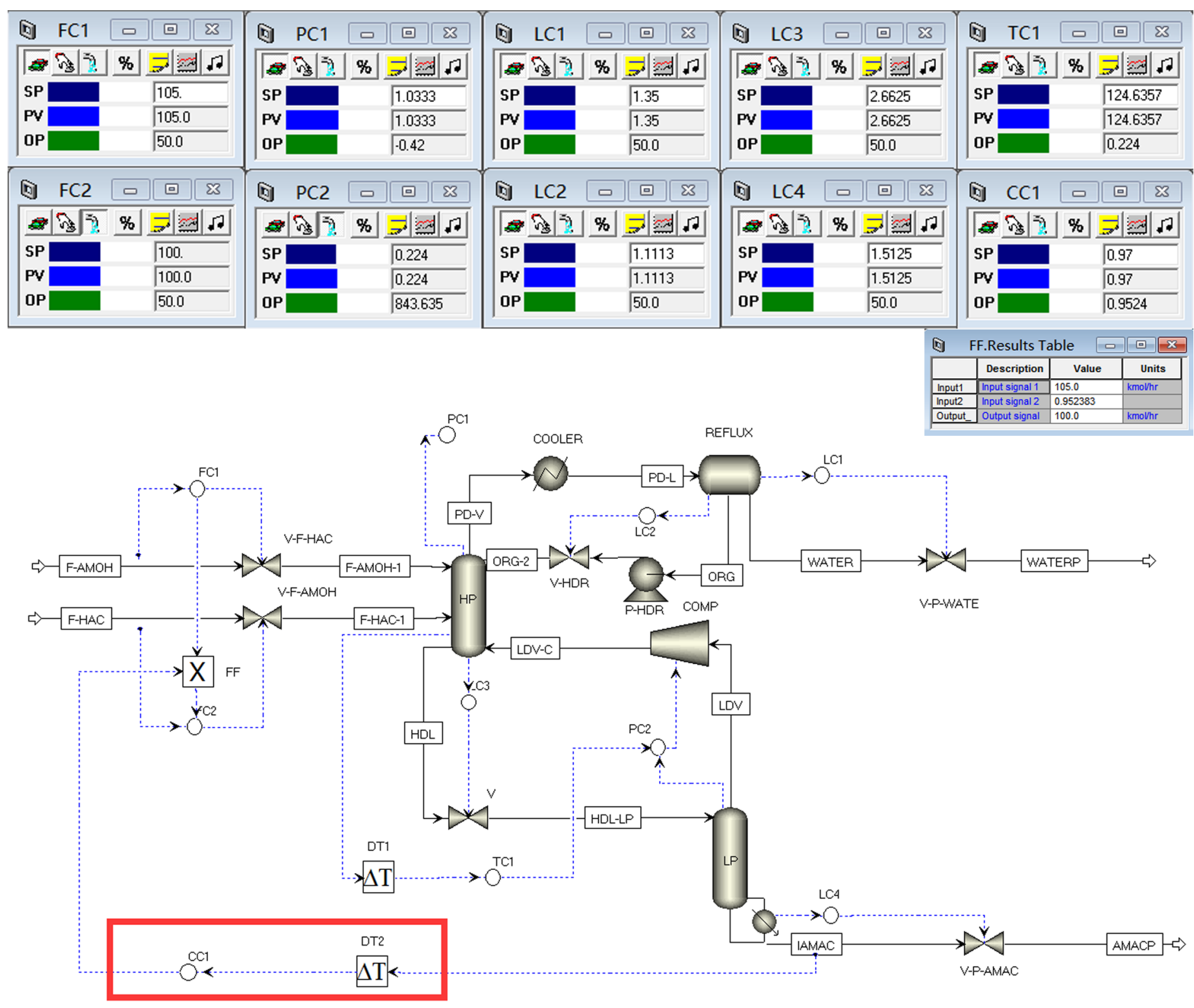

Figure 16. Improved control structure 1 (IC1) 

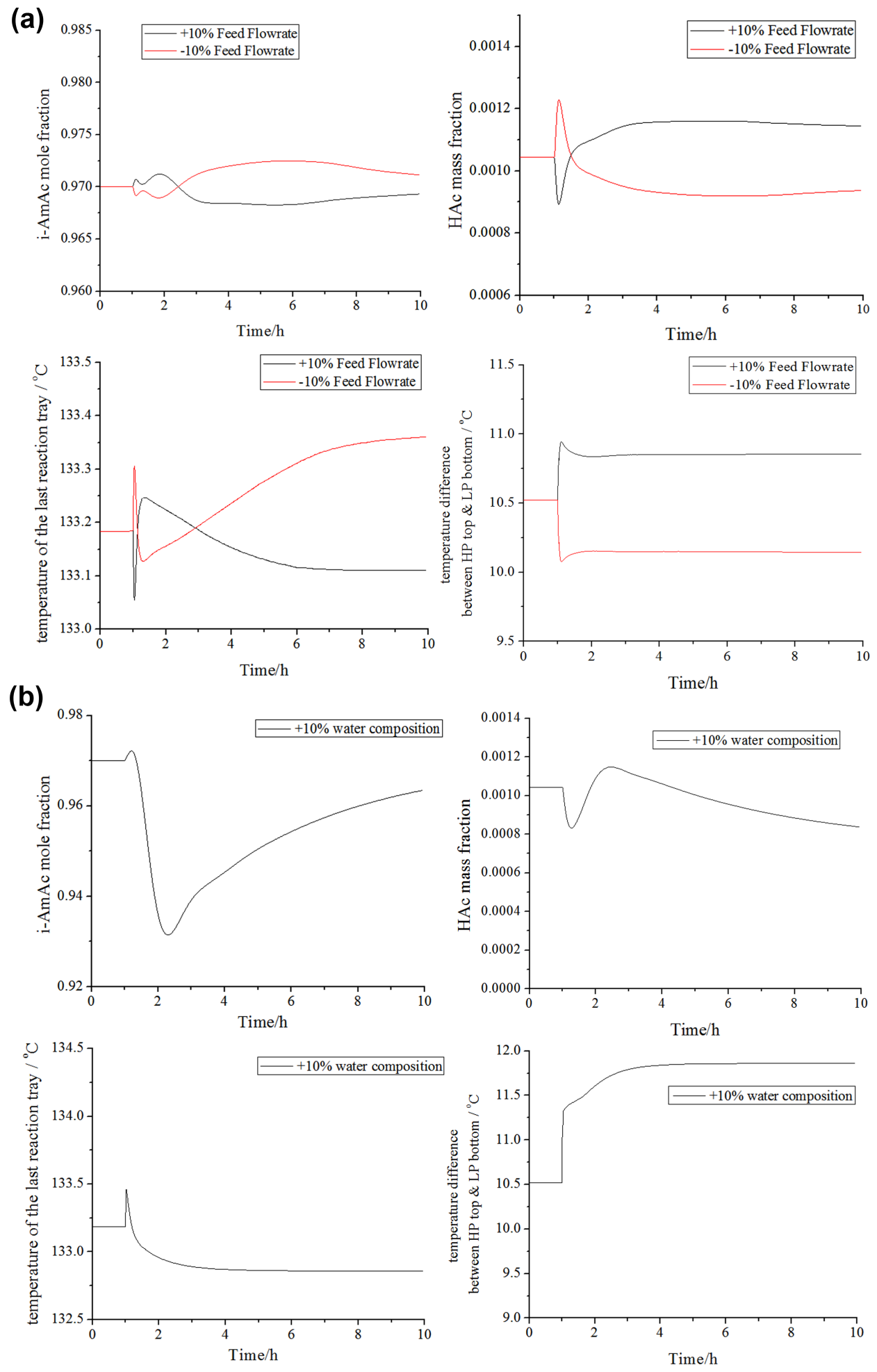

Figure 17. Control behaviors of the IC1 structure (a) with $\pm 10 \%$ disturbance of $\mathrm{i}-\mathrm{AmOH}$ feed flowrate (b) with $+10 \%$ disturbance of water composition in HAc feed stream 
Figure 17 reveals that, with the feed flowrate disturbance introduced, the parameters reach new stable values after around 3 hours, especially for the i-AmAc mole fraction in i-AmAc product shows quite small maximum dynamic deviation and residual error (less than $0.02 \mathrm{~mole} \%$ ). The residual error of temperature difference is reduced and no long reach the limit. The mass fraction of HAc in i-AmAc product had a maximum dynamic deviation at around 0.01 mass $\%$, but the product can satisfy the specification during the feed flowrate disturbance analysis. Under the disturbance of water composition, the two purity parameters show large maximum dynamic deviation. Considering the product purity goal of $<0.1$ acidity (equals to around $<0.15$ mass $\%$ HAc) and $97 \% \pm$ $0.5 \% \mathrm{i}$-AmAc mole fraction, the product purity is unacceptable even after 10 hours of the disturbance introduced. Based on the results of disturbance analysis, the control behaviors of IC1 are still unacceptable. An another improved structure should be considered.

\subsection{Improved Control Structure 2 (IC2)}

Considering that IC1 showed bad control behaviors under water composition disturbance, a feed HAc composition controller (CC2) is added to the process as shown in Figure 18. Such structure used a ratio controller to calculate the correction feed ratio by dividing the composition controller output (initial value of feed ratio) into feed HAc mole fraction. A dead time module with 3 min is added to the new composition controller, and the control behaviors under $\pm 10 \%$ feed flowrate disturbance and $+10 \%$ water composition disturbance in HAc feed stream were shown in Figure 19. 


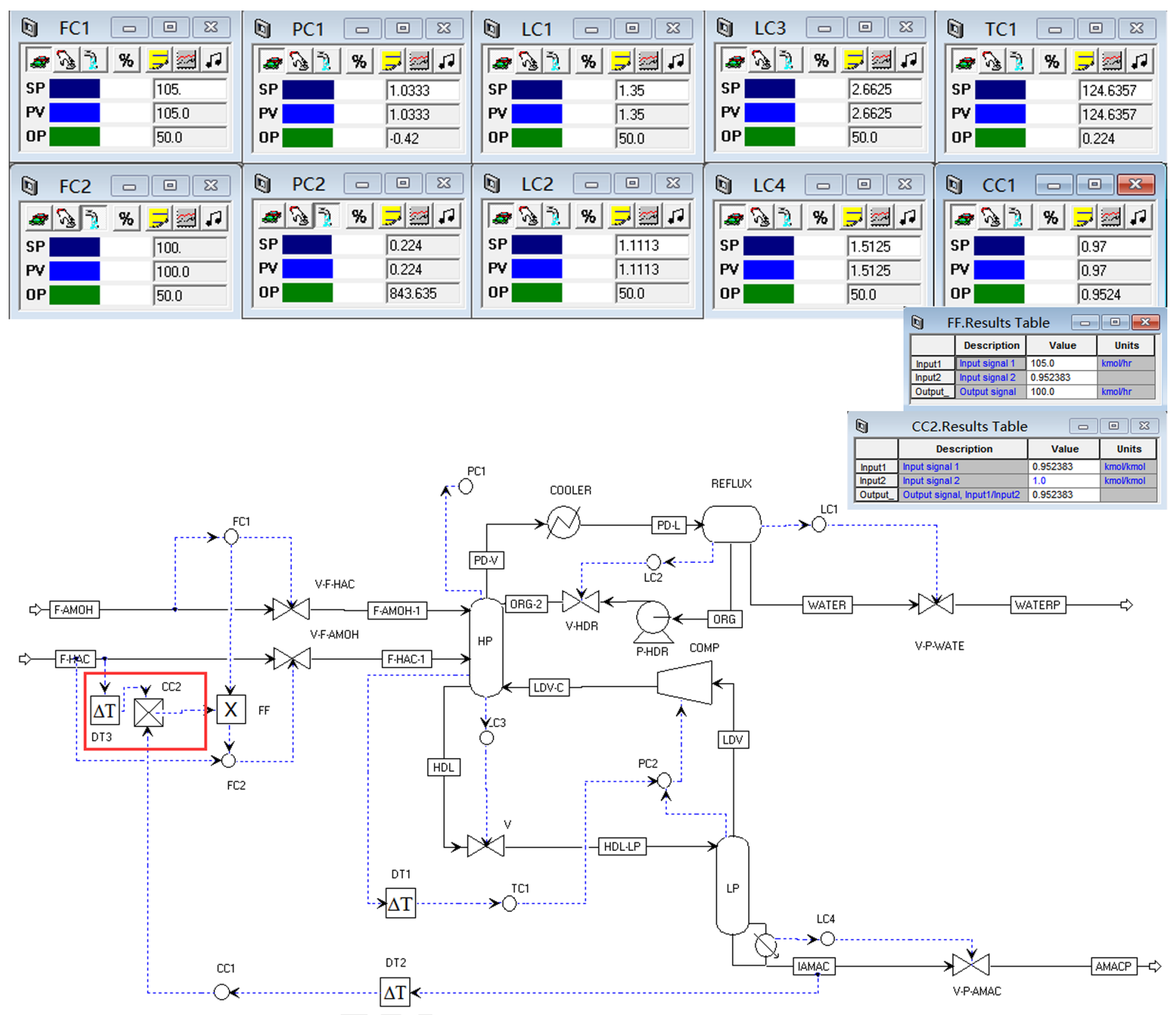

Figure 18. Improved control structure 2 (IC2) 

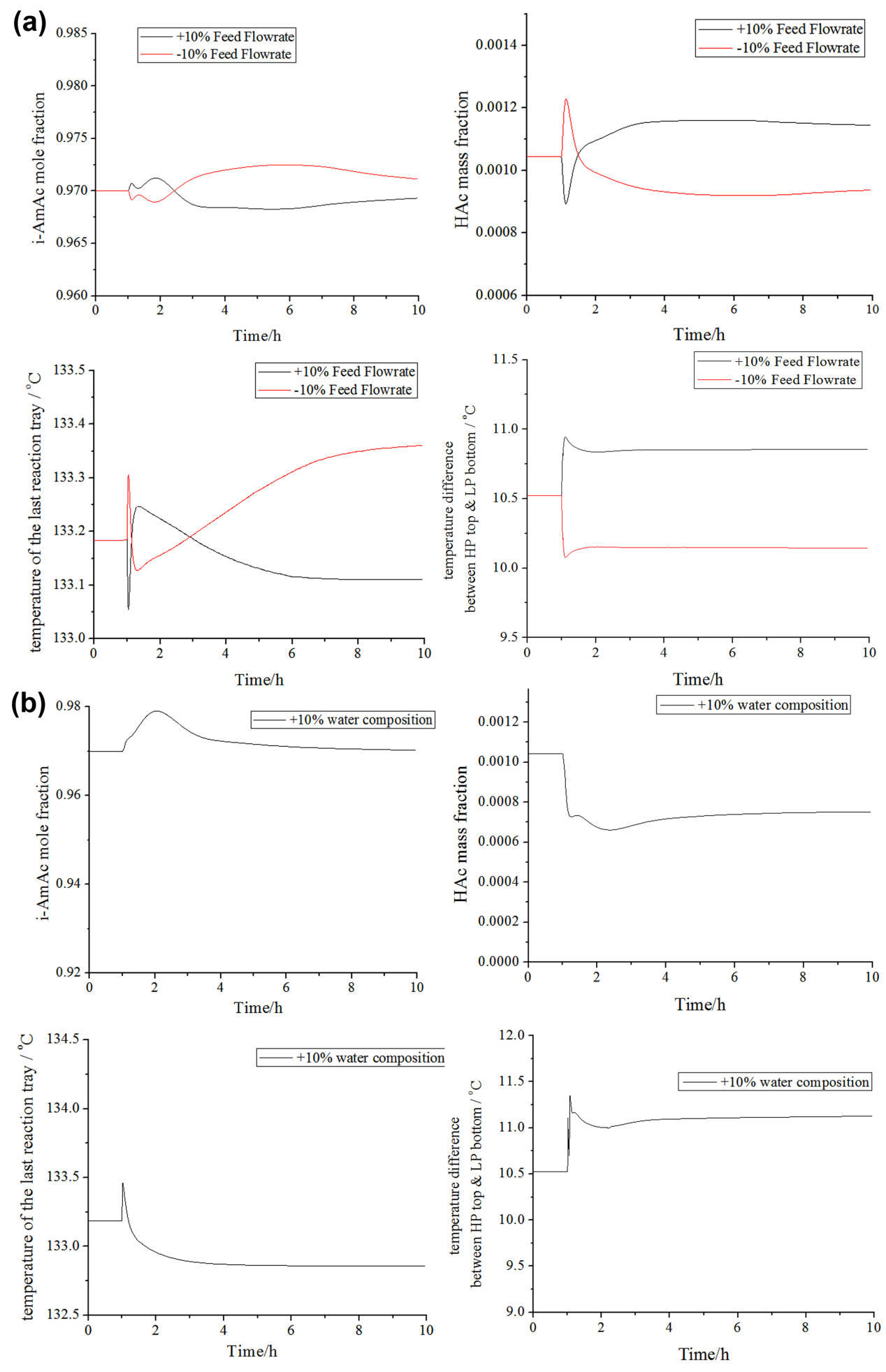

Figure 19. Control behaviors of the IC2 structure (a) with $\pm 10 \%$ disturbance of $\mathrm{i}-\mathrm{AmOH}$ feed flowrate (b) with $+10 \%$ disturbance of water composition in HAc feed stream 
Figure 19 reveals that IC2 show similar control behaviors compared with IC1 with the feed flowrate disturbance introduced. This is because the input of CC2 keeps a fixed value without feed composition disturbance. Under the disturbance of water composition, the two parameters show much smaller maximum dynamic deviation than IC1. The residual error of i-AmAc fraction has been eliminated, and considering the product purity goal of $<0.1$ acidity (equals to around $<0.15$ mass $\% \mathrm{HAc}$ ) and $97 \% \pm 0.5 \%$ i-AmAc mole fraction, the product purity is acceptable after 2 hours of disturbance analysis and both the fractions reach stable values after around 5 hours of the water composition disturbance introduced. Altogether, the IC2 structure shows better control behaviors with feed flowrate and water composition disturbance introduced. Though the residual error of HAc mass fraction has not been eliminated, this is not a problem since the specification of HAc just include the upper limit, which will not influence the product quality.

\section{Conclusion}

In this paper, a different pressure thermally coupled reactive distillation process for synthesis of isoamyl acetate was proposed. An economical optimization procedure was applied to the process and the optimized DPTCRD process showed $39.65 \%$ saving on operating cost and $1.25-19.05 \%$ saving on TAC with the payback period varied from 5 to 10 years.

Control structures for the DPTCRD process are also developed in this paper, and one basic control structure (BC) and two improved control structures (IC1, IC2) were proposed, and the control behaviors under feed flowrate disturbances were studied. The $\mathrm{BC}$ structure has a long settling time, and the maximum dynamic deviation and the residual error of the product purity are unacceptable. The IC1 structure achieve a quite small maximum dynamic deviation and residual error in the control of product mole fraction with feed flowrate 
disturbance, but the maximum dynamic deviation of the i-AmAc mole fraction with water composition disturbance introduced is unacceptable. Based on IC1, IC2 structure achieved similar behaviors with feed flowrate disturbance, and the control behaviors with water composition disturbance is improved significantly with short settling time, small dynamic deviation and elimated residual error, which means IC2 has best control behaviors among the three control structures.

\section{SUPPORTING FILES}

Formulas for TAC calculation.

\section{CORRESPONDING AUTHOR}

*Tel: +86 1385420 8340. E-mail: sunlanyi@upc.edu.cn.

**Tel + 44 (0) 161306 4384. E-mail: nan.zhang@manchester.ac.uk

\section{DECLARATION OF INTEREST}

None.

\section{ACKNOWLEDGMENT}

This work was supported by the National Natural Science Foundation of China (Grant No.21476261; Grant No.21506255), the Fundamental Research Funds for the Central Universities (Grant No. 18CX02120A) and the Promotive Research Fund for Excellent Young and Middle-aged Scientists of Shandong Province (Grant No. BS2014NJ010).

\section{REFERENCES}


[1] Cao, Y.; Hu, J.; Jia, H.; Bu, G.; Zhu, Z.; Wang, Y. Comparison of Pressure-swing Distillation and Extractive Distillation with Varied-diameter Column in Economics and Dynamic Control. J. Process Control. 2017, 49(1), 9-25. https://doi.org/10.1016/j.jprocont.2016.11.005

[2] Mali, S. V.; Jana, A. K. A Partially Heat Integrated Reactive Distillation: Feasibility and Analysis. Sep. Purif. Technol. 2009, 70(1), 136-139. https://doi.org/10.1016/j.seppur.2009.09.006

[3] Li. H.; Li, X.; Luo, M. Different Pressure Thermally Coupled Distillation Technology for Energy Saving. Chem. Indust. Eng. Prog. 2008, 27(7), 1125-1128. https://doi.org/10.3321/j.issn:1000-6613.2008.07.033

[4] Zhao, T.; Li, J.; Zhou, H.; Ma, Z.; Sun, L. A thermally coupled reactive distillation process to intensify the synthesis of isopropyl acetate. Chem. Eng. Process. 2018, 124(2), 97-108.

https://doi.org/10.1016/j.cep.2017.12.001

[5] Gao, X.; Wang, F.; Li, H.; Li, X. Heat-integrated Reactive Distillation Process for TAME Synthesis. Sep. Purif. Technol. 2014, 132(4), 468-478. https://doi.org/10.1016/j.seppur.2014.06.003

[6] Li, L.; Sun, L.; Wang, J.; Zhai, J.; Liu, Y.; Zhong, W.; Tian, Y. Design and Control of Different Pressure Thermally Coupled Reactive Distillation for Methyl Acetate Hydrolysis. Ind. Eng. Chem. Res. 2015, 54(12), 12342-12353. https://doi.org/10.1021/acs.iecr.5b03041

[7] Wang, S. J.; Wong, D. S. H.; Yu, S. W. Design and Control of Transesterification Reactive Distillation with Thermal Coupling. Comput. Chem. Eng. 2008, 32(12), 3030-3037.

https://doi.org/10.1016/j.compchemeng.2008.04.001 
[8] Welsh, F. W.; Murray, W. D.; Williams, R. E.; Katz, I. Microbiological and Enzymatic Production of Flavor and Fragrance Chemicals. Crit. Rev. Biotechnol. 1989, 9(1), 105-169. https://doi.org/10.3109/07388558909040617

[9] Romero, M. D.; Calvo, L.; Alba, C.; Daneshfar, A. A Kinetic Study of Isoamyl Acetate Synthesis by Immobilized Lipase-catalyzed Acetylation in N-hexane. J. Biotechnol. 2007, 127(1), 269-277. https://doi.org/10.1016/j.jbiotec.2006.07.009

[10] Krishna, S. H.; Divakar, S.; Prapulla, S. G.; Karanth, N.G. Enzymatic Synthesis of Isoamyl Acetate Using Immobilized Lipase from Rhizomucormiehei. J. Biotechnol. 2001, 87(5), 193-201. https://doi.org/10.1016/s0168-1656(00)00432-6

[11] Lee, L.; Lin, R. Reaction and Phase Equilibria of Esterification of Isoamyl Alcohol and Acetic Acid at 760 mm Hg. Fluid Phase Equilib. 1999, 165(11), 261-278. https://doi.org/10.1016/s0378-3812(99)00288-5

[121 Osorio-Viana, W.; Duque-Bernal, M.; Fontalvo, J.; Dobrosz-Gómez, I.; Gómez-García, M. A. Kinetic Study on the Catalytic Esterification of Acetic Acid with Isoamyl Alcohol over Amberlite IR-120. Chem. Eng. Sci. 2013, 101(9), 755-763. https://doi.org/10.1016/j.ces.2013.07.009

[13] Saha, B.; Teo, H. T. R.; Alqahtani, A. iso-Amyl Acetate Synthesis by Catalytic Distillation. Int. J. Chem. React. Eng. 2005, 3(1), 1250. https://doi.org/10.2202/1542-6580.1250

[14] Ali, S. S.; Hossain, S. S.; Asif, M. Dynamic Modeling of the Isoamyl Acetate Reactive Distillation Process. Pol. J. Chem. Technol. 2017, 19(3), 59-66. https://doi.org/10.1515/pjct-2017-0009 
[15] Luyben, W. L. Distillation Design and Control Using Aspen Simulation, 2nd ed., Wiley, Hoboken, NJ, 2013.

[16] Osorio-Viana, W.; Duque-Bernal, M.; Quintero-Arias, J. D.; Dobrosz-Gómez, I.; Fontalvo, J.; GómezGarcía, M. A. Activity Model and Consistent Thermodynamic Features for Acetic Acid-Isoamyl AlcoholIsoamyl Acetate-Water Reactive System. Fluid Phase Equilib. 2013, 345(5), 68-80.

https://doi.org/10.1016/j.fluid.2013.02.006

[17] Leyva, F.; Orjuela, A.; Gil, I.; Vargas, J.; Rodríguez G. Vapor-liquid equilibrium of isoamyl alcohol + isoamyl propionate and propionic acid+isoamyl propionate systems at 50.00, 101.33 and 150.00kPa. Fluid Phase Equilib. 2013, 356(10), 56-62. https://doi.org/10.1016/j.fluid.2013.07.024

[18] Douglas, J. M. Conceptual Design of Chemical Processes, McGraw-Hill, New York, 1988.

[19] Sun, L.; Wang, Q.; Li, L.; Zhai, J.; Liu, Y. Design and Control of Extractive Dividing Wall Column for Separating Benzene/Cyclohexane Mixture. Ind. Eng. Chem. Res. 2014, 53(4), 8120-8131. https://doi.org/10.1021/ie500291a

[20] Warren, D. S.; Daniel, R. L.; J. D. Seader; Soemantri, W. R. G; Rafiqul, G.; Ka, M. N. Product and Process Design Principles: Synthesis, Analysis and Evaluation, 4th ed., Wiley, 2004.

[21] Luo, H.; Bildea, C. S.; Kiss, A. A. Novel Heat-pump-assisted Extractive Distillation for Bioethanol Purification. Ind. Eng. Chem. Res. 2015, 54(2), 2208-2213. https://doi.org/10.1021/ie504459c 
[22] Hung, S.; Lee, M.; Tang, Y.; Chen, Y.; Lai I.; Hung, W.; Huang, H.; Yu, C. Control of Different Reactive

Distillation Configurations. AIChE J. 2006, 52(4), 1423-1440. https://doi.org/10.1002/aic.10743

[23] Luyben, W. L.; Yu, C. Reactive Distillation Design and Control, John Wiley \& Sons, 2008.

https://doi.org/10.1002/9780470377741 